\title{
Scenario Source Models and Strong Ground Motion for Future Mega- earthquakes: Application to Lima, Central Peru
}

\author{
by Nelson Pulido, Zenón Aguilar, Hernando Tavera, Mohamed Chlieh, Diana Calderón, Toru \\ Sekiguchi, Shoichi Nakai, and Fumio Yamazaki
}

\begin{abstract}
The 2011 moment magnitude $\left(M_{\mathrm{w}}\right) 9.0$ Tohoku-Oki Japan earthquake occurred in a region where giant megathrust earthquakes were not expected. This earthquake proved the difficulty in assessing seismic hazard by relying mainly on information from historical and instrumental seismicity. To help improve the seismic-hazard assessment for such rare events, we propose a methodology to estimate the slip distribution of future megathrust earthquakes based on a model of interseismic coupling distribution in subduction margins, as well as information of historical earthquakes, and apply the method to the central Peru region, Lima. The slip model obtained from geodetic data represents the large scale features of asperities within the megathrust, which is appropriate for simulation of long-period waves and tsunami modeling. For the simulation of a broadband strong ground motion, we add small scale heterogeneities to the source slip to be able to simulate high frequencies. To achieve this purpose, we propose broadband source models constructed by adding short-wavelength slip distributions obtained from a Von Karman power spectral density function, to the slip model inferred from interseismic geodetic data. Using these slip models and assuming several hypocenter locations, we calculate a set of strong ground motions for Lima and incorporate site effects obtained from microtremors surveys and geotechnical data. Our simulated average pseudospectral accelerations (period $0.3 \mathrm{~s}$ ) are above $1.5 \mathrm{~g}$ for wide areas in Lima, which may be critical in terms of damage of low- to midrise masonry and reinforced concrete buildings, which characterize the majority of buildings in Lima.
\end{abstract}

\section{Introduction}

Recent mega-earthquakes in Sumatra, 2004 (moment magnitude $M_{\mathrm{w}}$ 9.2), Chile, $2010\left(M_{\mathrm{w}} 8.8\right)$, and Japan, $2011\left(M_{\mathrm{w}} 9.0\right)$, have highlighted the enormous hazard associated with these giant subduction zone events. Hazard maps in Japan before the Tohoku-Oki earthquake did not include the possibility of a long recurrence time $\mathbf{M} 9$ earthquake in the Tohoku region as they heavily relied on historical and instrumental seismicity and did not sufficiently account for the longer paleoseismic record information (Frankel, 2013). To improve the seismic-hazard assessment for such rare events, it may be useful to incorporate other kinds of information such as crustal deformation at plate margins. In recent years, the development of Global Positioning System (GPS) and satellite radar interferometry make it possible to measure the strain buildup associated with plate coupling in many earthquakeprone regions around the world (Chlieh et al., 2004, 2011; Béjar-Pizarro et al., 2013). Recent studies have suggested that subducting plates are either locked or creeping aseismically, and that a patchwork of locked or coupled regions during the interseismic period may be related with asperities of earth- quakes (Konca et al., 2008; Moreno et al., 2010; Perfettini et al., 2010; Loveless and Meade, 2011). In this study, we propose a methodology to characterize source models of future megathrust earthquakes based on the spatial distribution of interseismic coupling (ISC) of subduction zones as well as information of historical earthquakes. We apply the method to the central Peru coast region that is a very active seismic region characterized by the fast subduction of the Nazca plate beneath the South American plate (Fig. 1). Seismic activity in Peru can be divided into two regions located north or south of the Nazca ridge that intersects the trench axis at $15^{\circ} \mathrm{S}$. The ridge is coincident with a region of low coupling, where the Nazca plate is believed to subduct aseismically (Perfettini et al., 2010; Chlieh et al., 2011) and therefore may act as a geomorphological barrier to seismic rupture propagation. The great 1868 earthquake in south Peru may have been the only known exception as the destructive tsunami observed in Pisco city during this earthquake suggests a fault model rupturing through the ridge from south to north (Okal et al., 2006). On the other hand, observed modified Mercalli intensity 


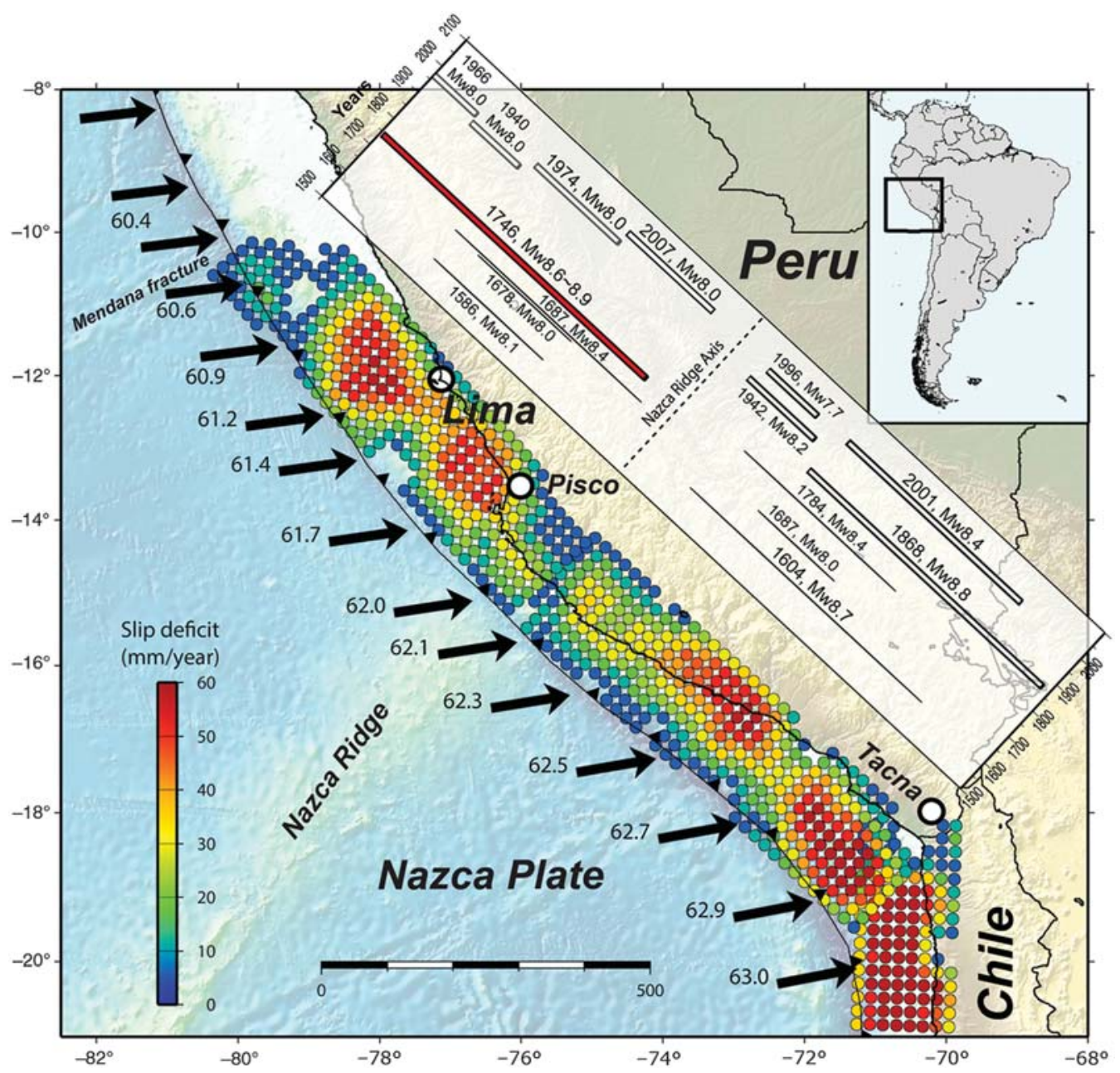

Figure 1. Slip deficit in Peru and northern Chile obtained from geodetic measurements, and historical earthquakes along the Nazca subduction zone in Peru (Chlieh et al., 2011). Black arrows are velocity vectors of the Nazca plate at the convergence margin with the South American plate (Chlieh et al., 2011).

(MMI) intensities of VI at Pisco and lower farther north (Silgado, 1978) also suggest that the 1868 earthquake rupture may have stopped not too far away from the ridge, so even in this case the ridge may have contributed to slow down fault rupture. Central Peru, north of the Nazca ridge, has been repeatedly affected by large earthquakes such as the great 28 October 1746 event, which is reportedly the greatest and worst subduction earthquake that the city of Lima has experienced since its founding. Intensity reports as well as a tsunami record suggest an $M_{\mathrm{w}}$ 8.6-9.2 for this earthquake (Silgado, 1978; Beck and Ruff, 1989; Beck and Nishenko, 1990; Dorbath et al., 1990; Tavera and Bernal, 2005). The 1746 earthquake was followed by a long period of quiescence until the start of a sequence of $M_{\mathrm{w}}$ 7-8 earthquakes in the twentieth century (1940, 1966, 1974, and 2007; Fig. 1). We use this information combined with an interseismic coupling model of the central Peru coast to develop a scenario for a megathrust earthquake that could likely affect the Lima metropolitan region, which constitutes $1 / 3$ of the Peruvian population with about 10 million people.
Previous efforts for developing scenario rupture models for crustal faults that are similar to the methodology proposed in our study include the 2008 southern California ShakeOut rupture model (Graves et al., 2010), which combined a longlength-scale slip distribution based on slip rates from paleoseismic studies with a short-length-scale stochastic model, and rupture models for a suite of Hayward fault scenario earthquakes (Aagaard et al., 2010), which combined long-length-scale slip distributions based on aseismic creep models with short-lengthscale stochastic distributions. Our study is the first attempt to combine long-length-scale slip characteristics obtained from interseismic coupling models in subduction zones with shortlength-scale slip distributions, for the estimation of fault-rupture scenarios for megathrust earthquakes.

\section{Scenario Earthquakes}

\section{ISC Model and Scenario Earthquake}

Interseismic coupling models in Peru and Chile were obtained by inverting velocities from GPS campaigns at 
(a)

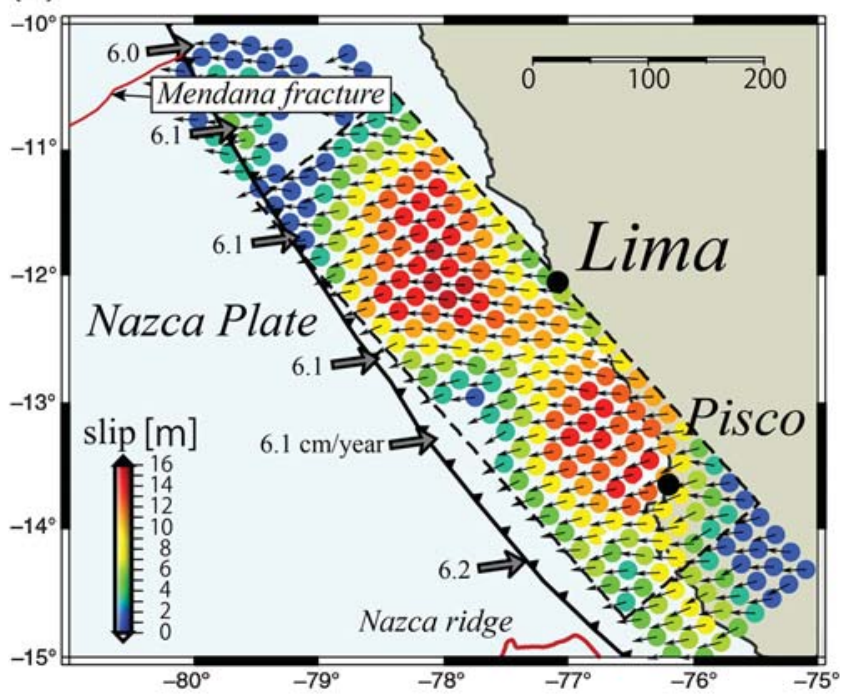

(b)

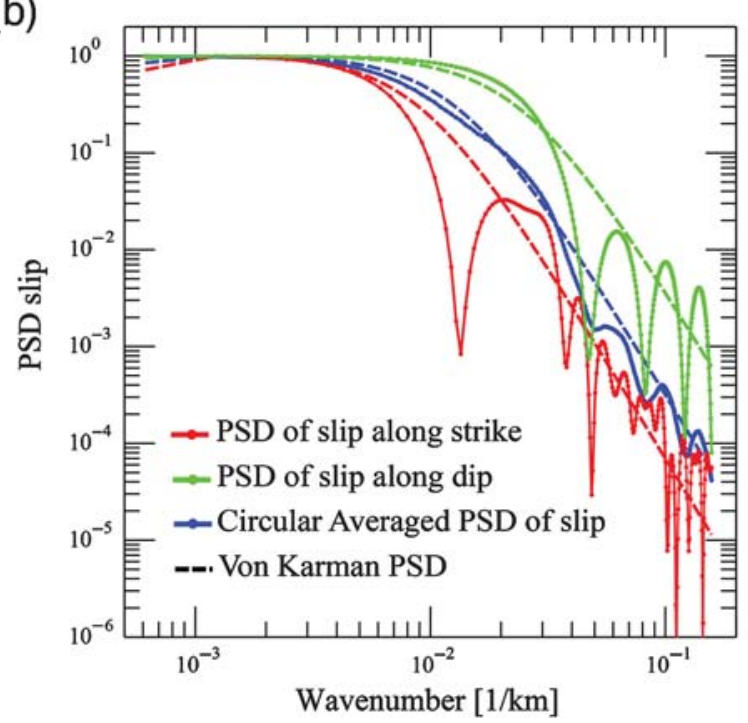

Figure 2. (a) Slip model obtained from the slip deficit in Figure 1 , and an interseismic period since the 1746 earthquake. (b) Normalized power spectral density (PSD) function of the slip distribution in (a), for wavenumbers along strike (red line), along dip (green line), and for a circular average of the 2D-PSD (blue line). The dotted lines indicate the fit of a Von Karman PSD function to the PSDs of slip. The black dashed rectangle denotes the clipped source model used for our scenarios.

87 sites surveyed from the period 1993-2003 in Peru (Chlieh et al., 2011). These data include interseismic seafloor deformations measurements obtained offshore Lima city from a deployment of seafloor acoustic transponders and inland GPS receivers (Gagnon et al., 2005). The ISC model is based on the assumption that convergence between the Nazca and South American plates is dominantly accommodated along the megathrust including $4 \mathrm{~mm} / \mathrm{yr}$ of back-arc shortening absorbed at the subandean fold and thrust belt regions (Chlieh et al., 2011). The inversion of geodetic measurements to obtain a heterogeneous ISC was performed using
Table 1

Velocity Model of Central Lima

\begin{tabular}{ccccrc}
\hline Depth $(\mathrm{km})$ & $V_{P}(\mathrm{~m} / \mathrm{s})$ & $V_{S}(\mathrm{~m} / \mathrm{s})$ & Density $\left(\mathrm{kg} / \mathrm{m}^{3}\right)$ & $Q_{P}$ & $Q_{S}$ \\
\hline 0 & 5800 & 3454 & 2675 & 763 & 381 \\
15 & 6200 & 3640 & 2761 & 851 & 425 \\
30 & 6800 & 3905 & 2912 & 991 & 495 \\
50 & 8000 & 4613 & 3291 & 1469 & 734 \\
\hline
\end{tabular}

$V_{P}$ values from Dorbath et al. (1990) and other parameters obtained from $V_{P}$ using empirical scalings by Brocher (2008).

a slab geometry with a dip of $15^{\circ}$ for the central Peru segment and was subdivided into cells of $20 \mathrm{~km} \times 20 \mathrm{~km}$. In each cell the coupling coefficient was allowed to vary from 0 to 1 . The results of ISC indicate the existence of two strongly coupled regions: offshore Lima and offshore Pisco city. Figure 1 shows the distribution of slip deficit rate, obtained by multiplying the ISC distribution by the plate convergence rate proposed by Kendrick et al. (2003). Assuming this interseismic process stands since the last great 1746 event, up to 2010, we obtained a cumulative slip deficit equivalent to an earthquake with an $M_{\mathrm{w}} 8.9$ (Fig. 2a) integrated over the 1746 rupture area and assuming a rigidity of $39 \mathrm{GPa}$. We choose that upper-bound scenario for a megathrust rupture in central Peru to reproduce some characteristics of the 1746 great event. It is likely that the twentieth century sequence of events from 1940 up to 2007 released a significant fraction of the slip deficit, estimated to be $50 \%$ by Chlieh et al. (2011). However, we cannot exclude that, in the next centuries, the four asperities that broke individually in the twentieth century seismic sequence will break simultaneously to reproduce an event as large as the 1746 earthquake.

\section{Slip Scenario Earthquake}

The source model of the scenario earthquake has a maximum slip of approximately $16 \mathrm{~m}$, the source dimensions are approximately $500 \mathrm{~km}$ along strike and $160 \mathrm{~km}$ along dip, and the grid spacing is $20 \mathrm{~km}$. The black-dashed rectangle denotes the source model used for our scenarios (Fig. 2a). The $M_{\mathrm{w}}$ calculated using a rigidity of $39 \mathrm{GPa}$ is $M_{\mathrm{w}} 8.9$. The rigidity was obtained as an average value at the scenario source region from the velocity model of Dorbath et al. (1991) (Table 1). This geodetic slip model (GSM) spans an area from the Nazca ridge, slightly south of the 2007 $M_{\mathrm{w}} 8.0$ Pisco earthquake source area, up to a latitude of $10.5^{\circ} \mathrm{S}$ where the Mendana fracture crosses the trench (Fig. 1). The GSM is characterized by a smooth distribution of asperities partly due to the large grid spacing employed in the model (Fig. 2a). This model can be appropriate for the simulation of long-period seismic waves (periods longer than $\sim 1 \mathrm{~s})$ as well as for tsunami modeling. However for the simulation of a broadband strong ground motion it is necessary to introduce small-scale complexities to the source slip to be able to simulate high-frequency ground motions. To achieve this purpose, we propose a broadband source model in which 
(a)

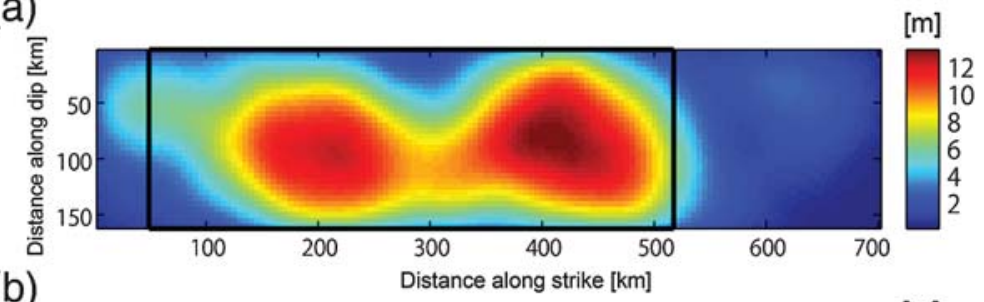

(b)

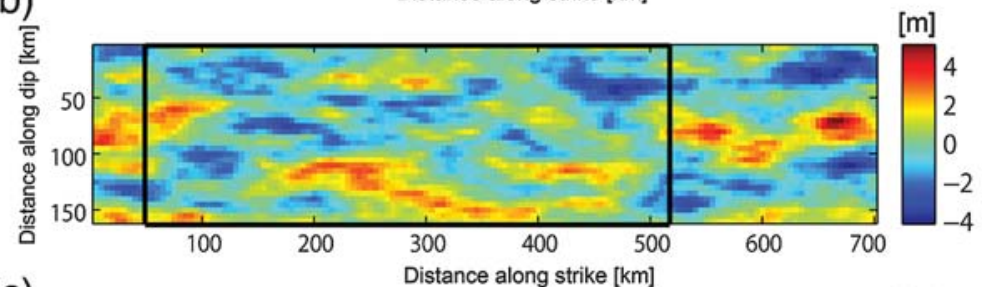

(c)

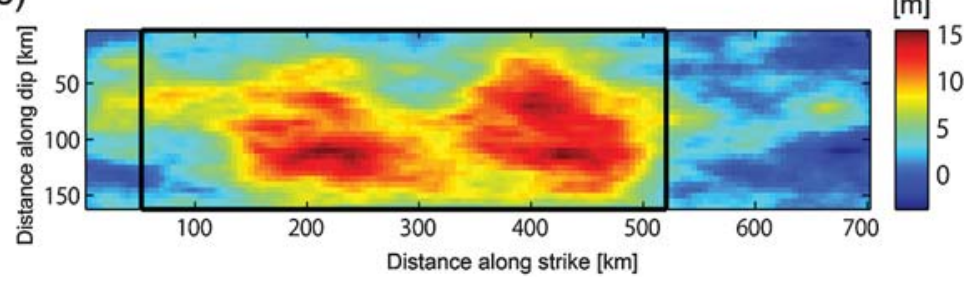

(d)

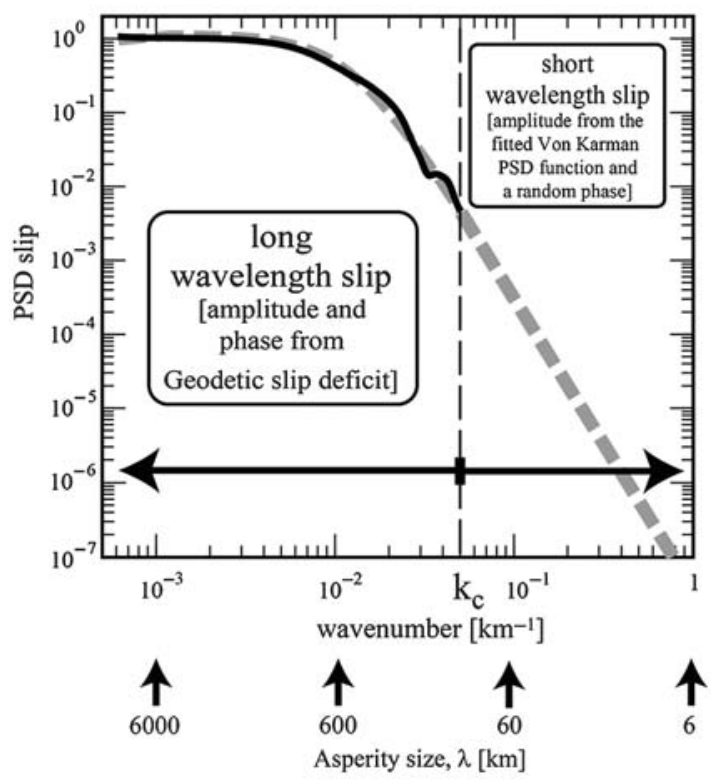

Figure 3. (a) Low-pass filtered slip distribution in Figure 2a (interpolated to a $5 \mathrm{~km}$ grid spacing). (b) Short-wavelength slip obtained by high-pass filtering the slip distribution obtained from the Von Karman PSD function of slip in Figure 2a (dashed blue line) extrapolated to high wavenumbers and using a random phase. (c) Broadband slip obtained by adding low- and high-wavenumber slips in (a) and (b). (d) Schematic explanation of the construction of the PSD for the broadband slip distribution in (c). $k_{\mathrm{c}}$ is the crossover wavenumber used to define the filter limits in (a) and (b). The black rectangles within (a), (b), and (c) denote the clipped source model used for simulations.

large scale features of the model are constructed from the GSM, and the short-wavelength slip distribution is obtained from spatially correlated random noise. To obtain the parameters of this short-wavelength slip, we first calculate the power spectrum density (PSD) of our GSM, along the strike and dip directions (red and green lines in Fig. 2b), as well as for a circular average (blue line in Fig. 2b), and then fit a Von Karman PSD function to the observed spectra:

$$
P\left(k_{\mathrm{s}}, k_{\mathrm{d}}\right)=\frac{a_{\mathrm{s}} a_{\mathrm{d}}}{\left[1+a_{\mathrm{s}}^{2} k_{\mathrm{s}}^{2}+a_{\mathrm{d}}^{2} k_{\mathrm{d}}^{2}\right]^{H+1}},
$$

in which $k_{\mathrm{s}}$ and $k_{\mathrm{d}}$ are wavenumbers along strike and dip, $a_{\mathrm{s}}$ and $a_{\mathrm{d}}$ are the autocorrelation distances along strike and dip, and $H$ is the Hurst exponent defining the spectral decay. Our fit to the PSD of the GSM yielded values of $110 \mathrm{~km}^{-1}$, $40 \mathrm{~km}^{-1}$, and 1 for $a_{\mathrm{s}}, a_{\mathrm{d}}$, and $H$, respectively (dashed lines in Fig. 2b). To calculate a broadband slip, we first interpolate the original GSM to a smaller grid interval, and apply a lowpass filter for wavenumbers smaller than a crossover wavenumber $\left(k_{\mathrm{c}}\right)$ equal to 0.05 , to get a long-wavelength slip distribution (Fig. 3a). Then we generate a correlated random slip model using the aforementioned Von Karman PSD function amplitudes (equation 1) and a random phase. We then apply a high-pass filter to this correlated random slip model for wavenumbers higher than $k_{\mathrm{c}}$, to get the short-wavelength slip (Fig. 3b). Finally, we add the long- and short-wavelength slips (shortest wavelength $\sim 10 \mathrm{~km}$ ) to obtain a broadband wavelength slip (Fig. 3c). The $k_{\mathrm{c}}$ value was selected to approximately correspond to the size of the long-wavelength asperity size (125 km; Fig. 3d), which is about five times the corner wavenumber of the GSM.

In Figure 4a, we compare the PSD of a slip model of the 2010 Maule earthquake, Chile (green line) (Pulido et al., 2011), with the PSD of our geodetic scenario slip for central Peru coast (red line). The similarity of these PSD's suggests that our methodology might be appropriate to characterize megathrust earthquakes in this region. On the other hand the PSD of broadband slip in Figure 3c (blue line in Fig. 4a) displays a richer content in amplitudes at smaller wavelengths (large wavenumbers) as compared with the PSD of GSM. This feature will help enrich the high-frequency generation of simulated strong ground motions.

\section{Broadband Slip for Central Peru}

To calculate several broadband slips to be used for the strong-motion simulations in central Peru, we computed a set of 12 short-wavelength slip models realizations and added them to the long-wavelength slip as outlined in Figure 3. For this purpose, we generate 12 sets of normally distributed random numbers with a zero mean and a standard deviation of one for a matrix corresponding to the source area used for the GSM. Next, we calculate their 2D fast Fourier transform (FFT), normalize it, multiply their spectral amplitude by the square root of the Von Karman PSD function of slip (equa- 
(a)
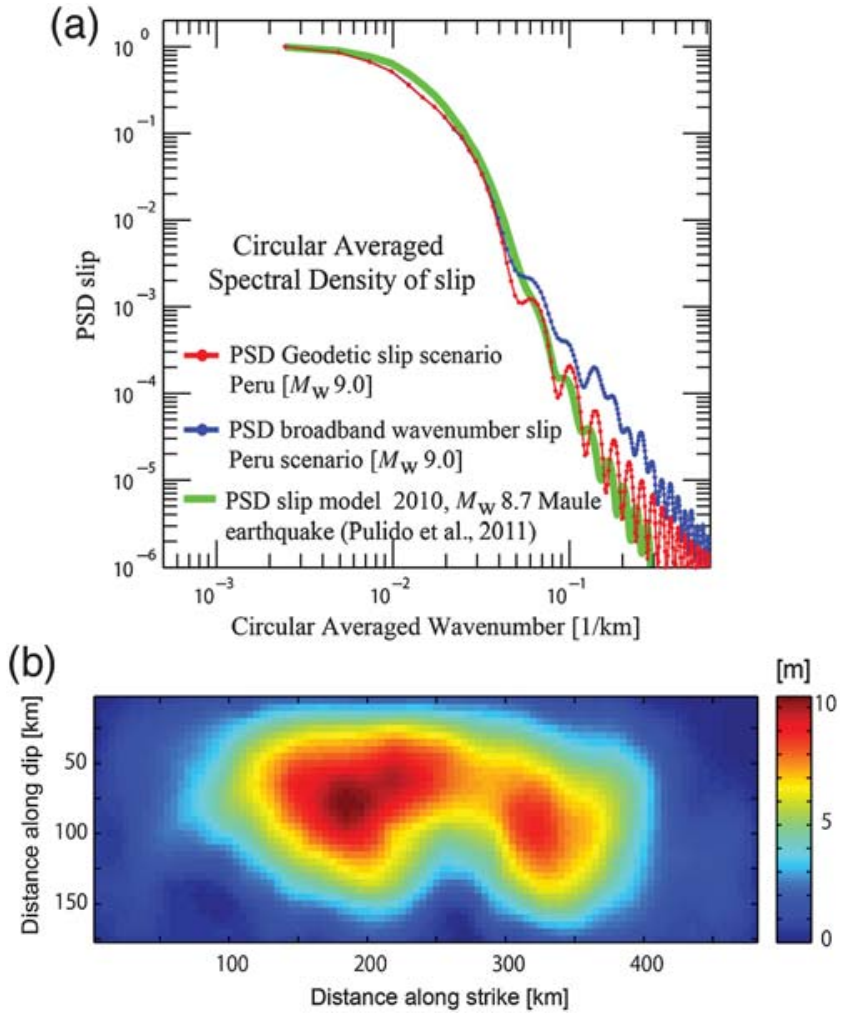

Figure 4. (a) Comparison of PSD of the geodetic slip in Figure $3 \mathrm{a}$ (red line), PSD for a slip model of the 2010 Maule earthquake (green line), and the broadband slip in Figure 3c (blue line). (b) Slip model of the 2010 Maule earthquake (Pulido et al., 2011).

tion 1), and get them back to the spatial domain by applying the inverse FFT. This procedure is equivalent to calculating the inverse FFT of a matrix of complex numbers whose amplitudes are defined by the PSD function of slip (equation 1) and considering a $2 \mathrm{D}$ random phase. The 12 broadband slip models used for the strong-motion simulations are shown in Figure 5. Slip distributions have been obtained for a subfault size of $10 \mathrm{~km}$.

\section{Strong-Motion Simulations}

\section{Strong-Motion Simulation Method and Parameters}

To perform the strong-motion simulations, we used an updated version of the hybrid methodology of Pulido and Kubo (2004). Their procedure combines a deterministic simulation of ground motion at low frequencies $(0.01-1 \mathrm{~Hz})$, with a semistochastic simulation at high frequencies (HFs) $(1-10 \mathrm{~Hz})$, and assumes a flat-layered 1D velocity structure. In Pulido and Kubo (2004), the source model was defined as a patchwork of rectangular-shaped asperities embedded in a finite fault with constant slip. In the present study, we modified their methodology to be able to handle a general distribution of slip, which is parameterized for a set of uniformly distributed point sources (subfaults). For the low frequencies (LFs), subfaults ground motions are calculated using the dis- crete wavenumber theory (Bouchon, 1981) and using a heterogenous distribution of rise time across the fault plane as detailed in equations (2) and (3) below. The total LF ground motion at a given site is obtained by summing the time-delayed contributions from all subfaults, by assuming a given rupture velocity and hypocenter location. At high frequencies, ground motion from subfaults is calculated using equations (2), (3), (4), and (5) in Pulido and Kubo (2004), by assuming a variable stress drop (absolute value) across the fault plane. We also incorporate a frequency-dependent radiation pattern value, as well as empirical envelopes of ground motion for subfaults, using equations (13)-(17) in Pulido and Dalguer (2009). Total HF ground motion at a given site is performed by applying the empirical Green's function method (Irikura, 1986), by assuming the same rupture velocity, hypocenter location, and rise times used for the LF. Broadband ground motion is obtained by adding LF and HF ground motions in the time domain. The broadband simulations for the present study are performed for the 0.05$30 \mathrm{~Hz}$ frequency range. The methodology has been extensively tested and validated in previous studies (Pulido and Kubo, 2004; Pulido et al., 2004; Sorensen, Atakan, et al., 2007; Sorensen, Pulido, et al., 2007; Pulido and Dalguer, 2009; Pulido et al., 2013).

To calculate the strong-motion simulations for the Lima Metropolitan region, we used the 12 broadband slip source models obtained as detailed in the previous section and assumed nine different locations of starting points of the rupture (white stars in Fig. 6a), yielding a total of 108 faultrupture scenarios. Hypocenter locations were determined based on results of Mai et al. (2005) indicating that earthquake ruptures tend to nucleate close to regions of large slip. The main parameters for the simulations are the slip, stress drop, and rise-time distributions across the fault plane, as well as the rupture velocity. A typical calculation of these parameters is shown in Figure 6. We calculated the stressdrop distributions following Ripperger and Mai (2004). Rise times of subfaults were assumed to be proportional to the square root of slip by constraining the fault average rise-time value with empirical scalings (Graves and Pitarka, 2010):

$$
t_{r i}=k s_{i}^{1 / 2},
$$

in which $k$ is the scaling factor between rise time and slip

$$
k=\frac{2.83 \times 10^{-7} M_{0}^{1 / 3}}{\frac{1}{n} \sum_{i=1}^{n} s_{i}^{1 / 2}}
$$

and $t_{r i}$ and $s_{i}$ are rise time (s) and slip (m) of the $i$ subfault, respectively, $n$ is the number of subfaults, and $M_{0}$ is the total seismic moment $(\mathrm{N} \cdot \mathrm{m})$. The rupture velocity was assumed as $72 \%$ of the average $S$-wave velocity at the source, and we added a 5\% fluctuation around the rupture front to enhance high-frequency radiation, which implies an advance or delay of the rupture front of $200 \mathrm{~m}$ with respect to the uniform 

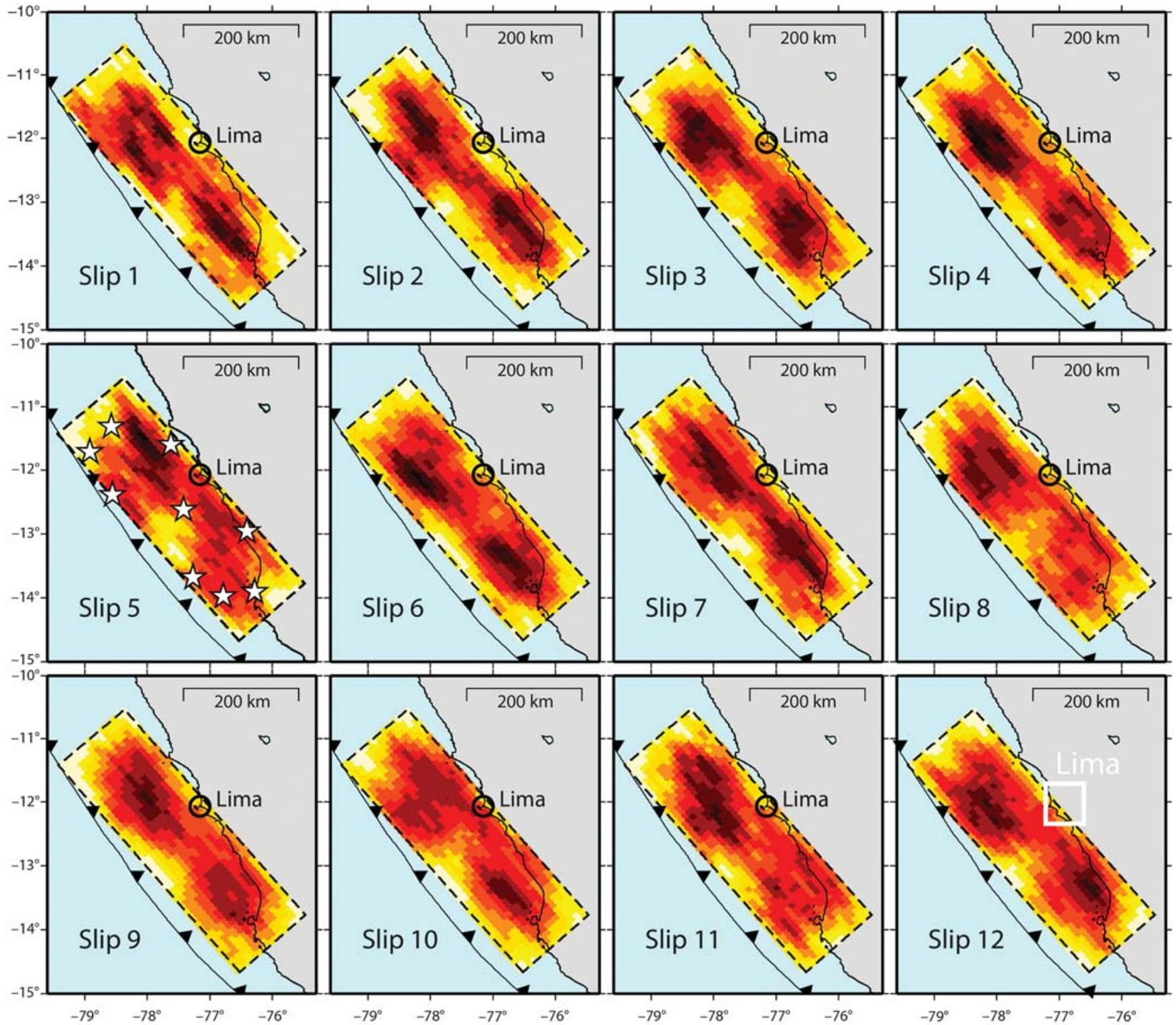

slip [m]

$\begin{array}{lllllllllllll}0 & 2 & 4 & 6 & 8 & 10 & 12 & 14 & 16 & 18 & 20\end{array}$

Figure 5. Broadband source models constructed by adding short-wavelength slip distributions obtained from a Von Karman PSD function with random phases to the slip model inferred from geodetic data. In the panel corresponding to Slip 5, we show the nine starting points of rupture used for our scenarios. The white rectangle in the bottom right panel corresponds to Slip 12 shows the strong-motion simulation domain in Lima.

rupture. Maximum frequency $f_{\max }$ was set to $10 \mathrm{~Hz}$. Parameters are summarized in Table 2.

The discretization scheme used in our source model was defined based on the selection of the appropriate number of subevents to be added by the empirical Green's function method, to obtain the total ground motion at a target site (Irikura, 1986; Irikura and Kamae, 1994). For our scenarios the number of subevents is equal to 3840 (48 subfaults along strike, 16 subfaults along dip, and a scaling factor of source time functions of large to small event of 5), which corresponds to a subfault size of 10 by $10 \mathrm{~km}$, and a difference in moment magnitude between large and small events of 2.4 units. We have found that this discretization scheme provides an adequate representation of the omega-square model of simulated ground motions in Lima. The choice of a subfault size of $10 \mathrm{~km}$ was also guided by the fact that the ISC model in Peru was estimated for a grid size of $20 \mathrm{~km}$ (Chlieh et al., 2011). To add small-scale slip heterogeneities, we interpolated the ISC model to half the grid size but avoided further interpolation that may lead to a spurious estimation of the corner wavenumbers in the PSD of slip (Causse et al., 2010) and bias the estimation of parameters in equation (1). 
(a)

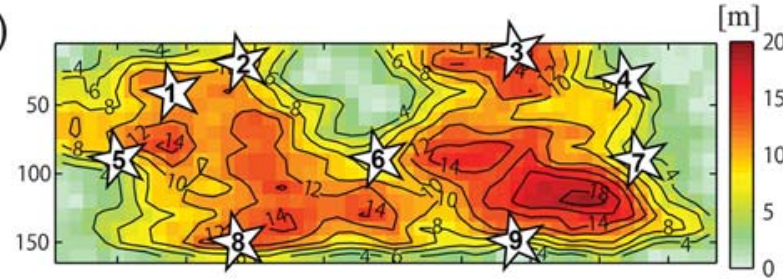

(b)

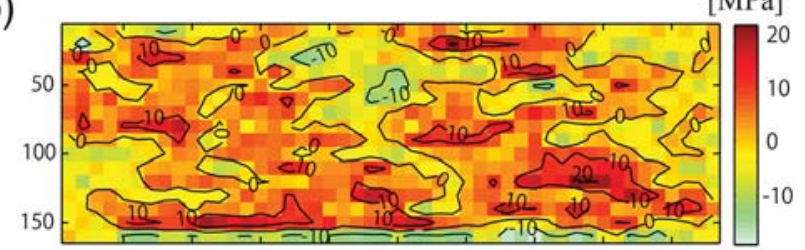

(c)

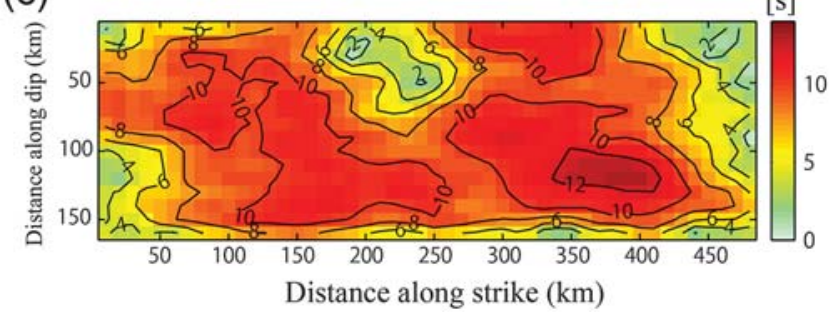

Figure 6. (a) Slip distribution across the fault plane for Scenario 5 . The nine starting points of the rupture are shown by white stars, (b) stress drop of slip in (a), and (c) rise time.

\section{Engineering Bedrock Strong-Motion Simulations in Lima}

The simulation domain spans an area of 50 by $55 \mathrm{~km}$ covering the entire Lima metropolitan region (white rectangle in Fig. 5). We calculated the east-west, north-south, and up-down components of strong ground motions at 169 grid points spaced every $5 \mathrm{~km}$ for the 108 scenarios. For the simulation of LF waveforms, we used a 1D crustal $P$-wave velocity model obtained for the Lima region (Dorbath et al., 1991) and calculated $V_{S}, Q$ values for the $P$ and $S$ waves as well as densities from empirical relationships (Brocher, 2008) (Table 1). The upper layer of this $1 \mathrm{D}$ velocity model is hereinafter referred to as the upper-crust layer $\left(V_{S}=3454 \mathrm{~m} / \mathrm{s}\right)$. For the computation of HF waveforms, we used an average $S$-wave velocity value, from the seismic source to the uppercrust layer, and a frequency dependent $Q$ value obtained for the Lima region $\left(Q=80 f^{0.63}\right)$ (Quispe et al., 2013) (Table 2). We add LF and HF to obtain broadband frequency seismograms at the upper-crust layer. Next, we computed accelerograms for a minimum $V_{S}$ of $400 \mathrm{~m} / \mathrm{s}$ (hereinafter referred to as engineering bedrock) by performing the convolution between the upper-crust layer seismograms with soil transfer functions at every grid point. Soil velocity models from $V_{S} 3454 \mathrm{~m} / \mathrm{s}$ to $V_{S} 400 \mathrm{~m} / \mathrm{s}$ were obtained based on microtremors array surveys performed at eight representative geotechnical zones within Lima (Fig. 7) (Calderon, 2012; Calderon et al., 2012). The depth of the half-space layer $\left(V_{S}=3454 \mathrm{~m} / \mathrm{s}\right)$ of these soil velocity models was set to
Table 2

Parameters for Strong-Motion Simulations

\begin{tabular}{lc}
\hline \multicolumn{1}{c}{ Parameter } & Value \\
\hline Grid size $(\mathrm{km})$ & 10 \\
Subfaults along strike, dip & 48,16 \\
Sampling period (s) & 0.01 \\
Strike/dip/rake $\left(^{\circ}\right)$ & $319 / 15 / 55.7$ \\
Stress-drop distribution & From slip model \\
Rise-time distribution & From slip model \\
Rupture velocity $(\mathrm{km} / \mathrm{s})$ & 2.87 \\
Radiation pattern frequencies & 1,5 (Pulido and Dalguer, 2009) \\
$\quad f_{1}, f_{2}(\mathrm{~Hz})$ & 10 \\
$f_{\text {max }}(\mathrm{Hz})$ & 3.99 \\
Average $S$-wave velocity $(\mathrm{km} / \mathrm{s})$ & 3.0 \\
Average density $\left(\mathrm{T} / \mathrm{m}^{3}\right)$ & (Quispe et al., 2013) \\
Anelastic attenuation $(Q)$ & Boore (2003) \\
Geometrical spreading & \\
\end{tabular}

$1.5 \mathrm{~km}$ based on information from a wide-angle seismic reflection line performed at the subduction margin off-Lima (Krabbenhoft et al., 2004) (Fig. 7). Transfer functions at every grid point were estimated by assigning the transfer functions obtained at the closest microtremors array measurement site. Transfer functions do not include information of soil layers shallower than $10 \mathrm{~m}$, as amplifications for those soils layers were estimated by a different approach, as we will explain in the next section. Figure 8 shows the simulated peak ground acceleration (PGA) values for the 12 slip scenarios averaged for the nine rupture starts in each case. We obtained that slip model number 5 yielded the largest ground motions in Lima. This feature can be explained by the fact that compared to other scenarios, Slip 5 contains the largest values of slip $(\sim 8 \mathrm{~m})$ for subfaults immediately beneath the city (Fig. 5) and therefore generated the severest ground motions. Figure 9 shows the simulated PGAs for Slip 5 and for all rupture nucleations. The largest PGA's are obtained for shallow rupture nucleations (i.e., ruptures 2 and 3 in Fig. 9), which enhance the directivity toward Lima. Deep rupture nucleations (i.e., ruptures 8 and 9 in Fig. 9) generate the lowest PGA's at Lima.

\section{Strong-Motion Simulations in Lima Including Shallow Site Effects}

We calculated the PGA and peak ground velocity (PGV) ground-motion maps for Lima by including shallow site amplifications, at a grid interval of $250 \mathrm{~m}$. For that purpose, we used an empirical relationship between the average $V_{S}$ for the shallowest $10 \mathrm{~m}$ of soil $\left(A V_{S 10}\right)$ and ground-motion amplifications with respect to the engineering bedrock (Fig. 10a,b) (Sekiguchi et al., 2013). Ground-motion amplifications were obtained as the average $(0.05 \sim 1 \mathrm{~s})$ of transfer functions from a dataset of 105 shallow soil velocity profiles in Lima, which were interpolated to a grid of $250 \mathrm{~m}$ based on $A V_{S 10}$ (Sekiguchi et al., 2013). The $A V_{S 10}$ map of Lima at a $250 \mathrm{~m}$ grid was obtained using information on horizontal-to-vertical ratios of microtremors (at $\sim 500$ measurement points), ground 
(a)
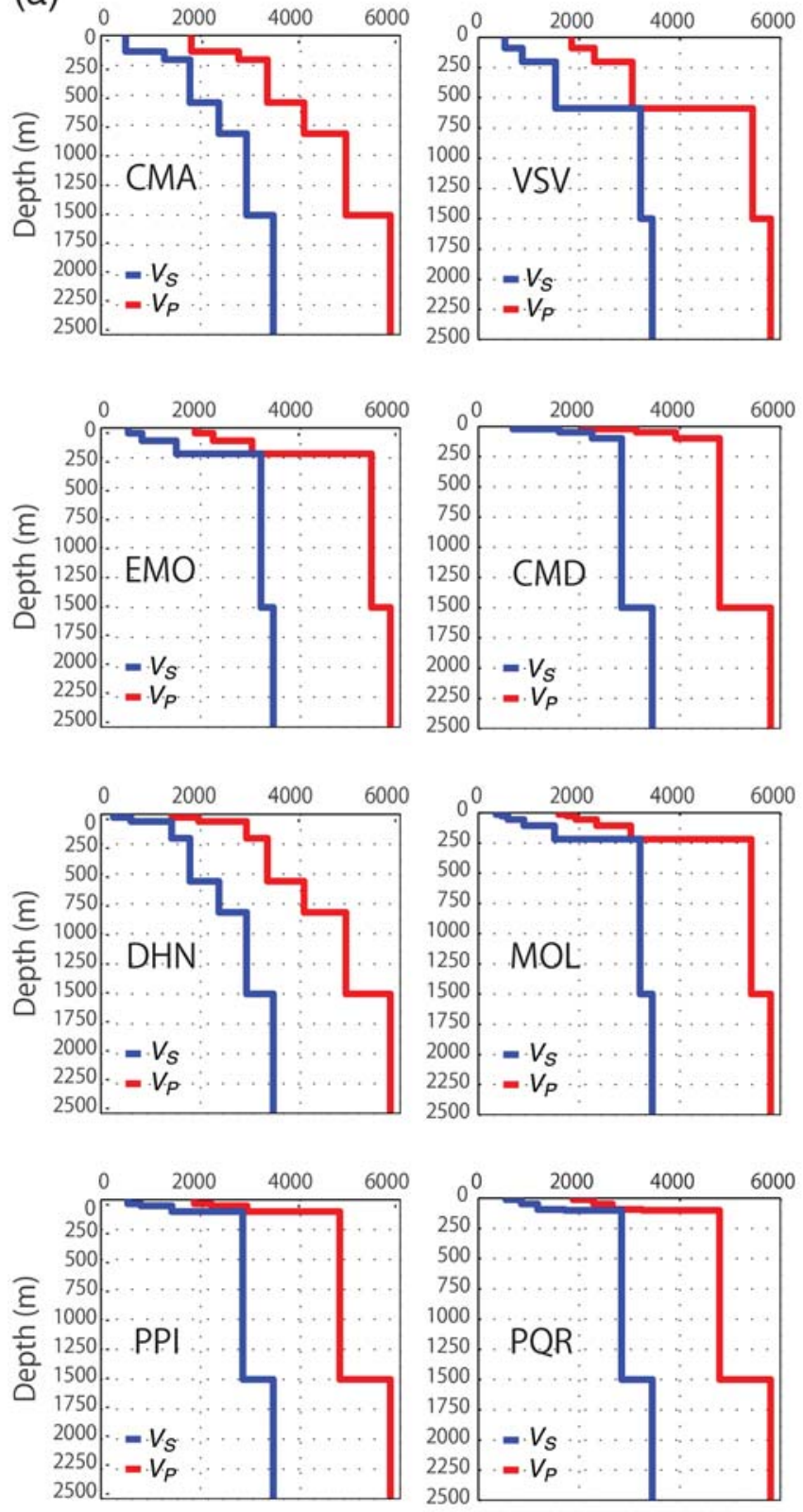

(b)
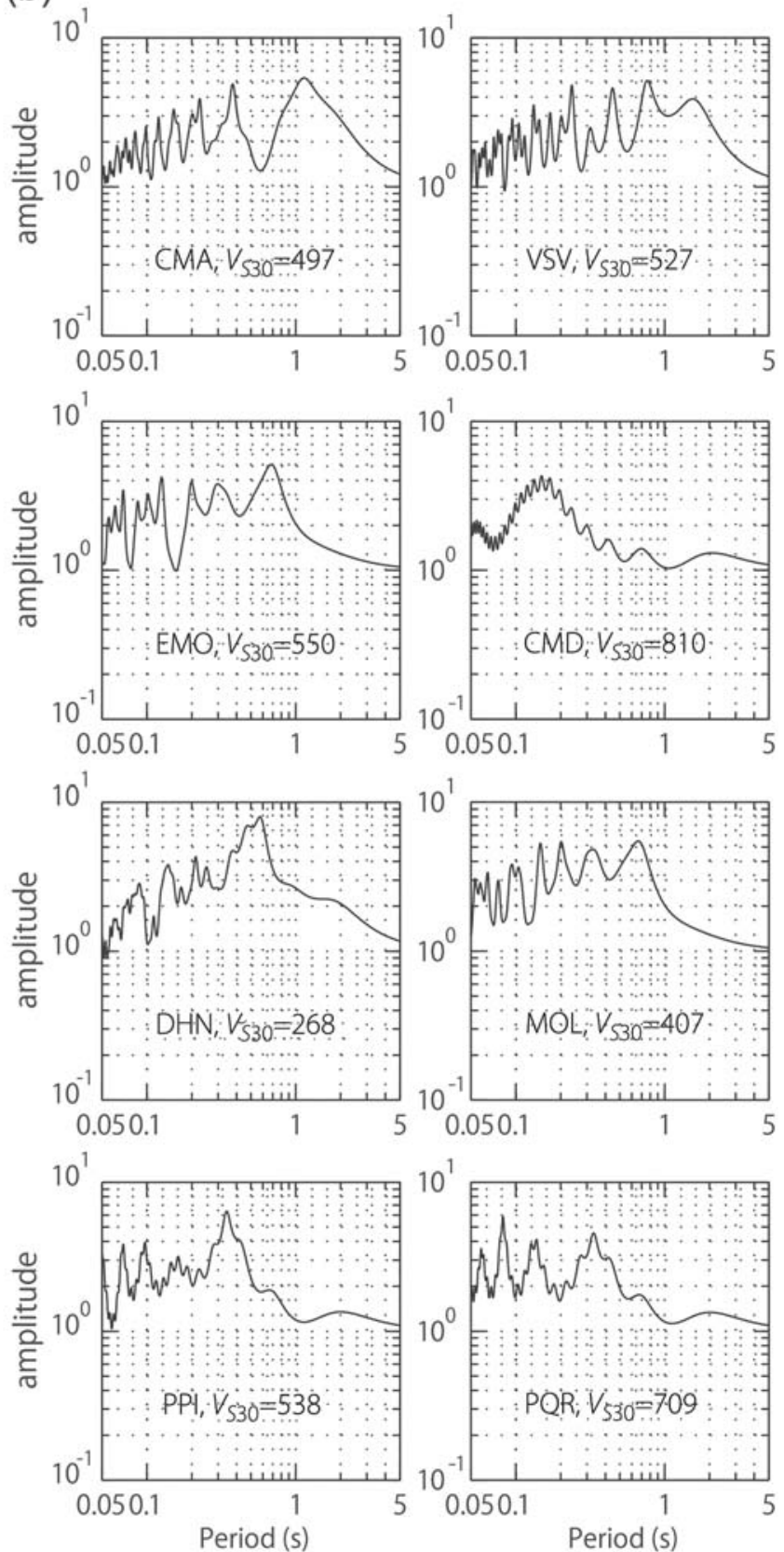

Figure 7. (a) Velocity models from the upper-crust layer $\left(V_{S}=3454 \mathrm{~m} / \mathrm{s}\right)$ to the engineering bedrock $\left(V_{S} \sim 400 \mathrm{~m} / \mathrm{s}\right)$ at eight sites in Lima, obtained from array microtremors measurements (Calderon et al., 2013). See location of the sites in Figure 10. (b) Transfer functions of the velocities in (a).

elevation, and soil types information in Lima (Sekiguchi et al., 2013). In Figure 11a,b, we show the average PGA and PGV distributions in Lima for all scenarios, as well as the ground-motion values one standard deviation away from the mean. Average ground motions for metropolitan Lima reach values around $700 \mathrm{~cm} / \mathrm{s}^{2}$ and $70 \mathrm{~cm} / \mathrm{s}$ for the Callao region (around CMA in Fig. 11) and are above $400 \mathrm{~cm} / \mathrm{s}^{2}$ for wide areas of the city including downtown Lima (around PQR in Fig. 11), as well as the business area in San Isidro. However simulated ground motions can be as large as $1000 \mathrm{~cm} / \mathrm{s}^{2}$ and $100 \mathrm{~cm} / \mathrm{s}$ in Callao and
Villa El Salvador (around CMA and VSV in Fig. 11) for ground motions one standard deviation above the mean. Average within-event (considering scenarios as distinct events) standard deviations of simulated PGA and PGV are 44\% and 32\% (in natural log units) for the Lima metropolitan region. These values are consistent with event-corrected single-station standard deviations of observed data from various tectonic regions around the world (Rodriguez-Marek et al., 2013).

It is also important to check nonlinearity effects of soils in simulated ground motions. For that purpose, we applied 

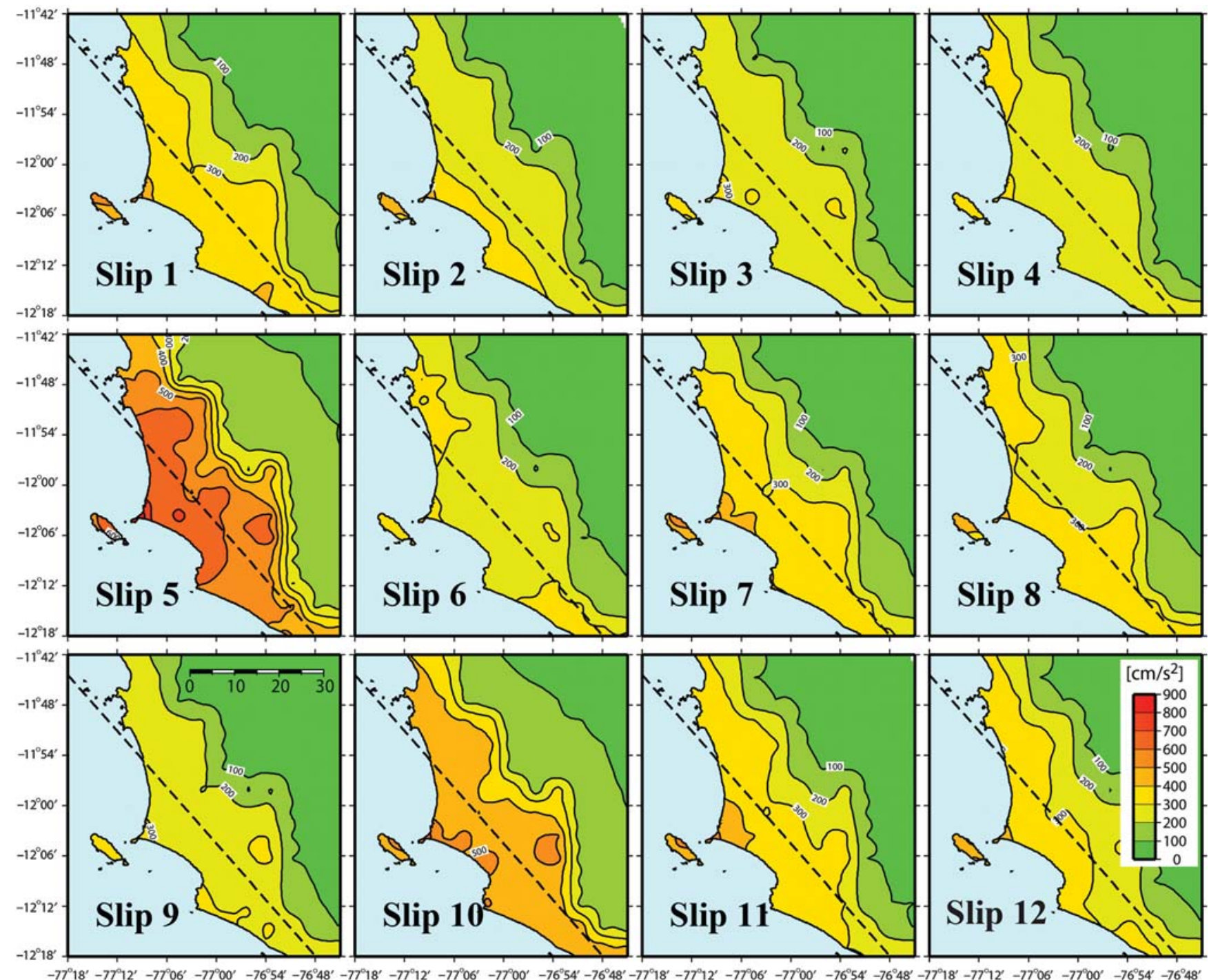

Figure 8. Simulated peak ground acceleration (PGA) values in Lima for the 12 slip scenarios averaged for the nine rupture starts in each case, for an engineering bedrock soil condition $\left(V_{S}=400 \mathrm{~m} / \mathrm{s}\right)$.

the equivalent-linear methodology (Schnabel et al., 1972) to calculate accelerograms at the surface incorporating nonlinear response of soils at the eight sites detailed in Figure 7. Our results indicate that the reduction in PGA and PGV is very small for most sites, which might have been expected considering that soil in Metropolitan Lima is mainly composed of very hard gravels (average $V_{S}$ for the shallowest $30 \mathrm{~m}, V_{S 30}$, above $400 \mathrm{~m} / \mathrm{s}$ ), and therefore nonlinear effects of soil for simulated strong ground motions in this study are negligible.

\section{Comparison with Records from the 1974 and 1966 Earthquakes}

Two large earthquakes occurred in the subduction zone offshore Lima in $1966\left(M_{\mathrm{w}} 8.0\right)$ and in $1974\left(M_{\mathrm{w}} 8.0\right)$. These events were recorded by a strong-motion station at "Parque de la Reserva" (PQR), in central Lima. We calculated broad- band strong motions at this site for all scenarios, incorporating the site response by convolving the upper-crust ground motions with a soil transfer function (calculated from the upper crust to a $V_{S} 360 \mathrm{~m} / \mathrm{s}$ ) obtained for this site (Calderon et al., 2012). In Figure 12a, we may observe several simulated accelerograms at $\mathrm{PQR}$ in blue and the observed strongmotion records during the 1974 earthquake (red) and 1966 earthquake (orange) for the north-south component. In dark blue, we display the simulated accelerogram obtained from Slip 5 and hypocenter number 1, which has a PGA value approximately equal to the average $\mathrm{PGA}$ plus one sigma at $\mathrm{PQR}$ (Fig. 11). The waveform in blue corresponds to Slip 7 and hypocenter number 1 , which has a PGA approximately equal to the average PGA at PQR (Fig. 11). The waveform in light blue also corresponds to Slip 7 and hypocenter number 1 but at the upper-crust layer. We can observe that the PGA amplitudes of the scenarios are about 2 to 3 times larger than the 

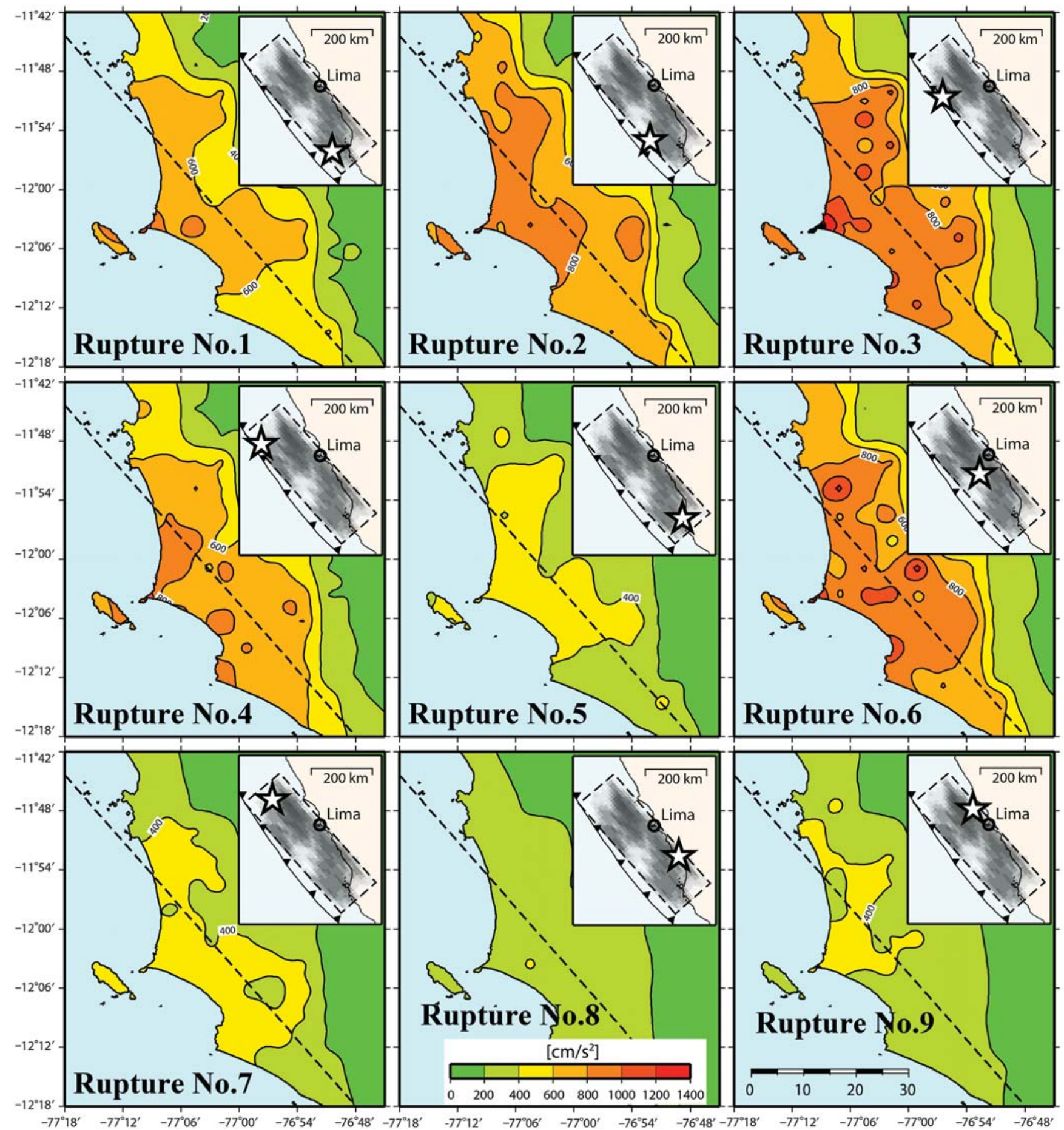

Figure 9. Simulated PGAs for Slip 5 and for all rupture nucleations, for an engineering bedrock soil condition $\left(V_{S}=400 \mathrm{~m} / \mathrm{s}\right)$. Inset on each panel shows the location of the starting point of the rupture in each case.

values observed at $\mathrm{PQR}$ during the 1966 and 1974 earthquakes. A similar observation can be made from the comparison of PGV waveforms (Fig. 12b). We can also observe that the simulated PGV and PGA values for the upper-crust waveforms for Slip 7 and hypocenter number 1 (waveforms in light blue in Fig. 12), are about 2 to 3 times smaller than the simulations that incorporate site amplifications for the same scenario (waveforms in blue in Fig. 12).

In Figure 13a,b, we can observe the acceleration and velocity response spectra for all the waveforms detailed in Figure 12. We can see that the spectral amplitudes of the simulated waveforms are as large as four times the values observed during the 1974 and 1966 earthquakes at PQR. 

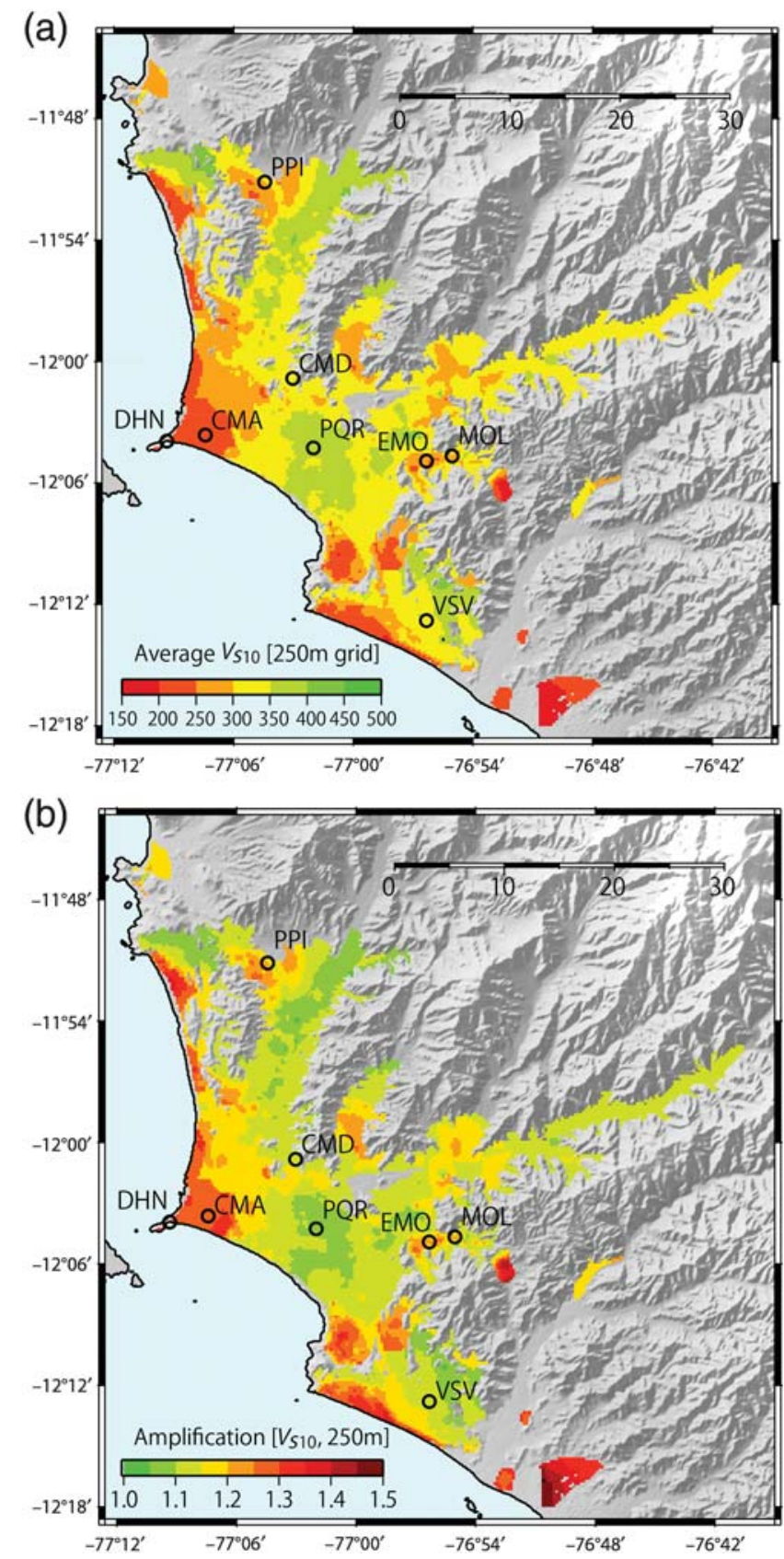

Figure 10. (a) Average $V_{S}$ for the shallowest $10 \mathrm{~m}$ of soil $\left(A V_{S 10}\right)$ in Lima (Sekiguchi et al. 2013). (b) Amplifications with respect to the engineering bedrock in Lima, defined as the average amplifications $(0.05 \sim 1 \mathrm{~s})$ of the transfer functions at each grid point $\left(V_{S} \sim 400 \mathrm{~m} / \mathrm{s}\right)$ (Sekiguchi et al., 2013).

All the simulated spectra for our scenarios at $\mathrm{PQR}$ have a large spectral peak at a period around $0.35 \mathrm{~s}$, which is also a clear feature of the north-south component of observed acceleration and velocity spectra for the 1974 and 1966 earthquakes (Fig. 13). This peak is also observed in the transfer function at PQR (Fig. 7b), suggesting that it is due to site effects. In Figure 13, we also can observe that at long periods (above $5 \mathrm{~s}$ ), the velocity response spectra for the seismic bedrock (light blue line), and the spectra incorporating site ef- fects (in particular for Slip 7 and hypocenter number 1) are very similar. Considering that the soil transfer function of $\mathrm{PQR}$ above $5 \mathrm{~s}$ displays no amplification (Calderon et al., 2012), these observations may indicate that ground motions are largely dominated by the source characteristics at this period range.

\section{Response Spectra in Lima}

We estimated the response spectra at metropolitan Lima for a grid every $250 \mathrm{~m}$, including site amplifications. To attain this goal, we first calculated the response spectra of the waveforms obtained for an engineering bedrock condition (5 km grid and 5\% damping) and interpolated them to points for which $A V_{S 10}$ information is available $(\sim 250 \mathrm{~m}$ grid, Fig. 10a). Next, we multiplied the simulated velocity response spectra $\left(S_{v}\right)$ with empirical soil amplifications, which were obtained for Lima city as a function of $A V_{S 10}$ and period (Fig. 14) (Sekiguchi et al., 2013). We interpolated the spectra to a constant period interval $(0.01 \mathrm{~s})$ and smoothed them using a running average window of $0.1 \mathrm{~s}$ of length. We finally calculated the pseudospectral accelerations (PSA) from $S_{v}$ (PSA $=S_{v} \times 2 \times \pi /$ period). The maps of average PSA and $S_{v}$ (vectorial summation of simulated east-west and north-south components) in metropolitan Lima for all scenarios and for selected values of period are shown in Figures 15 and 16, respectively. We can see that for wide areas in Lima the average PSA can reach values between 1.0 and $2.4 \mathrm{~g}$ for periods from 0.1 to $0.4 \mathrm{~s}$ (Fig. 15), reaching its maximum value at a period of $0.3 \mathrm{~s}$. This could be a critical issue in terms of damage if an earthquake of the characteristics considered in this study hits Lima, taking into account that the majority of structures in metropolitan Lima are typically low- to midrise masonry or reinforced concrete buildings (1-6 stories) (Matsuoka et al., 2013). Large values of $S_{v}(100-200 \mathrm{~cm} / \mathrm{s})$ were also obtained at Lima for periods from 1 to $2 \mathrm{~s}$ for the Callao district in central Lima, as well as for the Villa El Salvador district in southern Lima (Fig. 16). These periods would likely affect high-rise buildings $(\sim 10$ stories and above), which are not common at these locations (Matsuoka et al., 2013).

\section{Discussion}

The methodology proposed in this study to estimate slip scenarios for megathrust earthquakes is based on the assumption that the distribution of interseismic coupling in subduction margins is a good indicator for potential coseismic slip distribution of future earthquakes. Some studies of the 2010 Maule earthquake support this hypothesis (Moreno et al., 2010; Pulido et al., 2011), even though the debate is still active as other studies indicate a limited overlap between seismic gap and coseismic slip (Lorito et al., 2011). A comparison of several source models for the Maule earthquake show, however, that there is a large uncertainty on the location of regions of large slip (i.e., Delouis et al., 

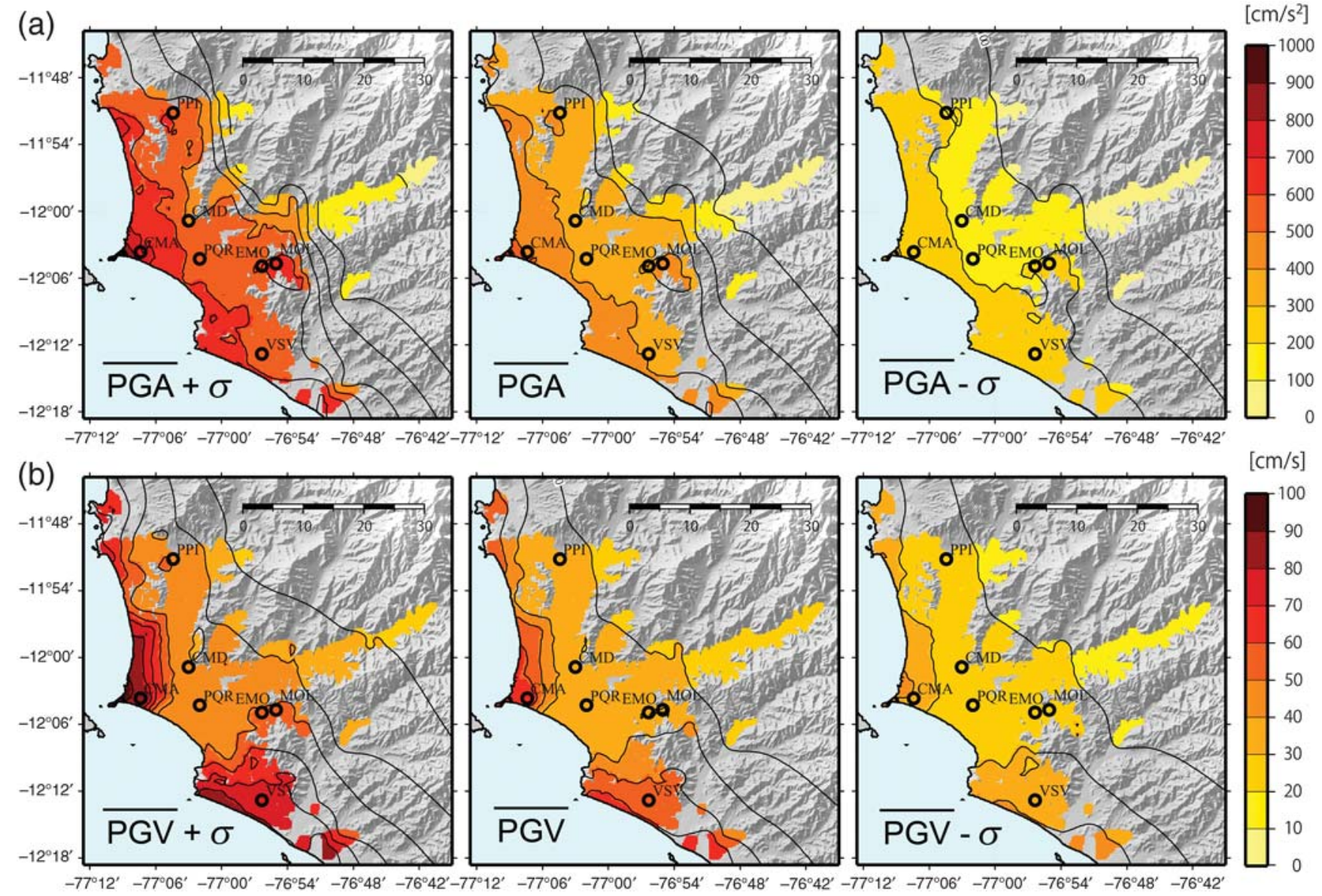

Figure 11. (a) Average PGA distributions in Lima for all scenarios, as well as the ground-motion values one standard deviation away from the mean. (b) Same for the peak ground velocity (PGV). All values include shallow site effects.
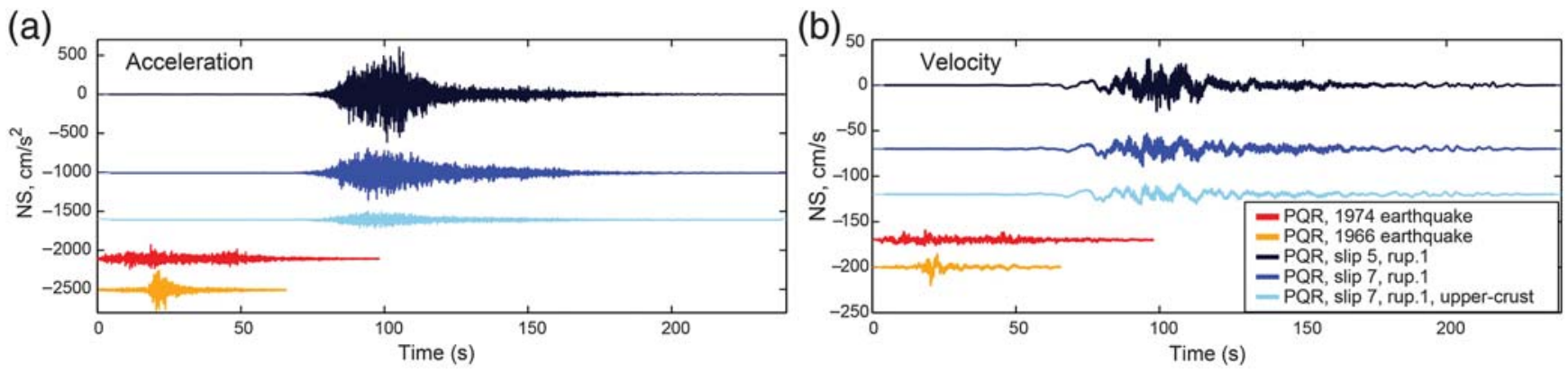

Figure 12. (a) Simulated accelerograms for the north-south component at Parque de la Reserva (PQR), for Slip 5 and hypocenter number 1 (dark blue), and Slip 7 and hypocenter number 1 (blue), including shallow site effects, and Slip 7 and hypocenter number 1 at the uppercrust layer (light blue). The accelerograms in red and orange correspond to records at PQR from the 1974 and 1966 Lima earthquakes, respectively. (b) Same as in (a) but for velocity.

2010; Lorito et al., 2011; Pulido et al., 2011; and Lay et al., 2010), so a definite conclusion based on this earthquake alone is difficult due to the uncertainties involved. On the other hand there are many other examples of coincidence between coseismic slip and interseismic coupling for worldwide subduction zones such as in Sumatra (Chlieh et al., 2008; Konca et al., 2008), in Japan (Hashimoto et al., 2009; Loveless and Meade, 2011), and in Chile (Moreno et al., 2010). In addition, the 2012 megathrust earthquake below the Nicoya Peninsula in Costa Rica $\left(M_{\mathrm{w}} 7.6\right)$ also occurred in the heart of a previously identified locked patch of the Cocos-Caribbean plate interface (Protti et al., 2013), providing strong supporting evidence for the coincidence of coseismic slip and high interseismic coupling areas. This earthquake was unique in that it ruptured a region at the Cocos-Caribbean plate interface where the subduction zone is 
(a)
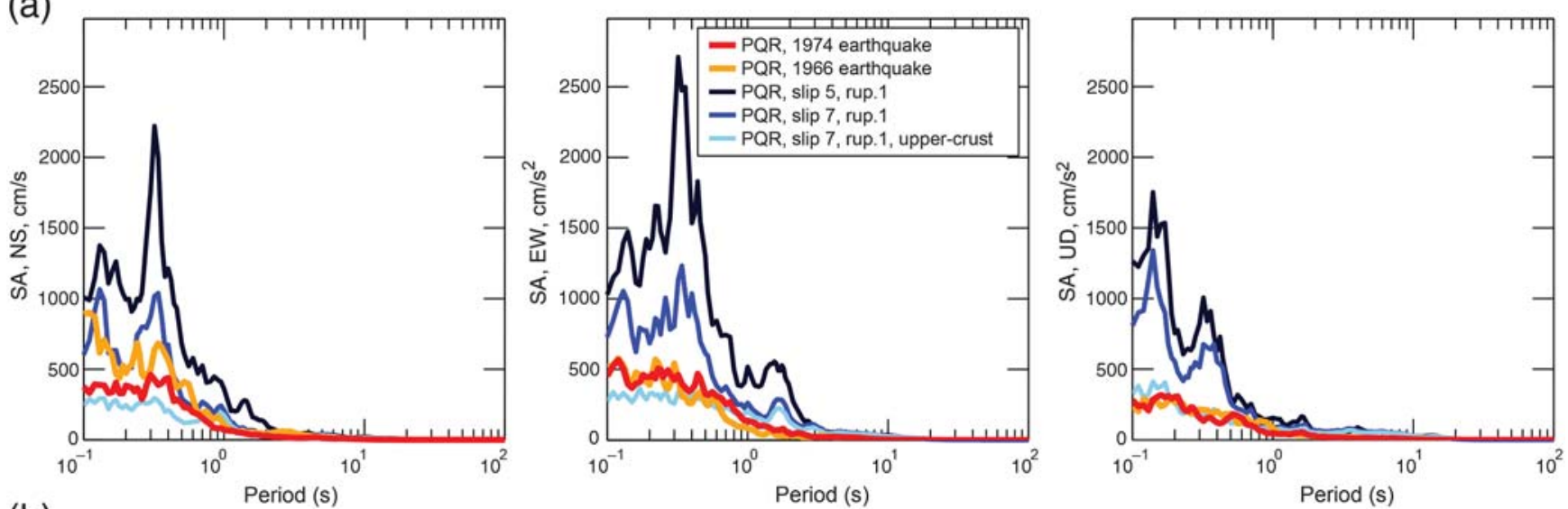

(b)
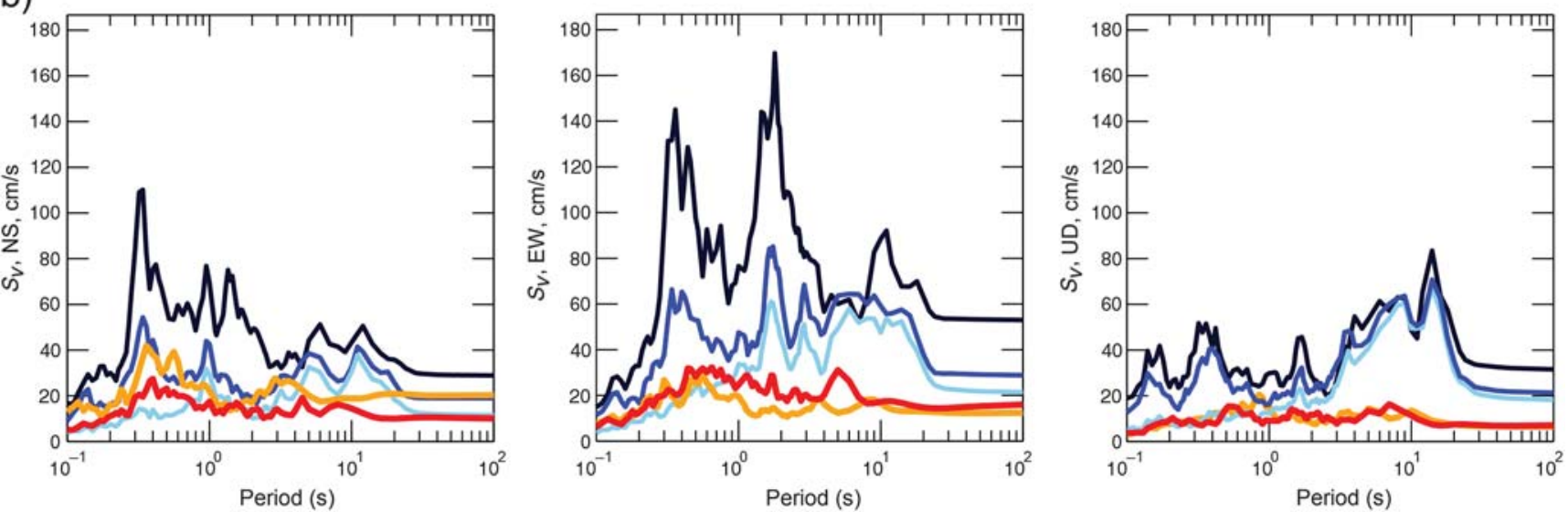

Figure 13. (a) Acceleration response spectra of the simulated north-south accelerograms at $P Q R$ for a 5\% damping, for the waveforms in Figure 12 (same color code used). The response spectra in red and orange correspond to records at PQR from the 1974 and 1966 Lima earthquakes. (b) Same as in (a) but for velocity response spectra.

overlaid by the Peninsula and was densely instrumented before the earthquake, allowing a high spatial resolution image of the plate coupling and coseismic slip (Protti et al., 2013). However, in general, resolution of plate coupling distribution as well as slip models of earthquakes in subduction regions is limited because they are typically based on land measurements away from the trench axis of seismogenic zones, making estimation of shallow coupling very difficult. To fill this gap, efforts to instrument ocean margins are currently being addressed in Japan (Okada, 2013), Canada, and the United States (Jones, 2014), so it is expected that monitoring at the sea bottoms will drastically improve our knowledge about seismogenesis in subduction zones in the near future.

Besides information from geodetic measurements, recent studies have also indicated a strong correlation between spatial distribution of seismicity rate of earthquakes in the Gutenberg-Richter law ( $b$-value) and coseismic slips during the 2004 Sumatra and 2011 Tohoku-Oki mega-earthquakes (Nanjo et al., 2012). Nanjo et al. (2012) found a decade scale decrease in $b$-value preceding the earthquakes, for regions coincident with high coseismic slip zones, suggesting that the $b$-value could be an important indicator of an impending great earthquake and therefore could be a valuable source

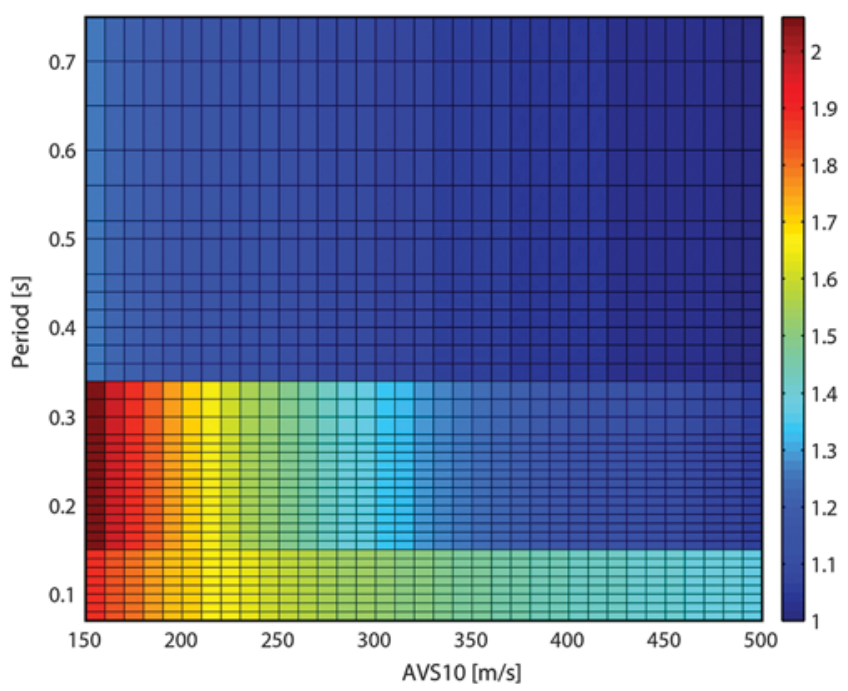

Figure 14. Empirical soil amplifications (color scale) for Lima city as a function of $A V_{S 10}$ and period (Sekiguchi et al., 2013).

of information for the estimation of slip scenarios. Other sources of information for this purpose may also include global trench-parallel gravity variations (Song and Simons, 

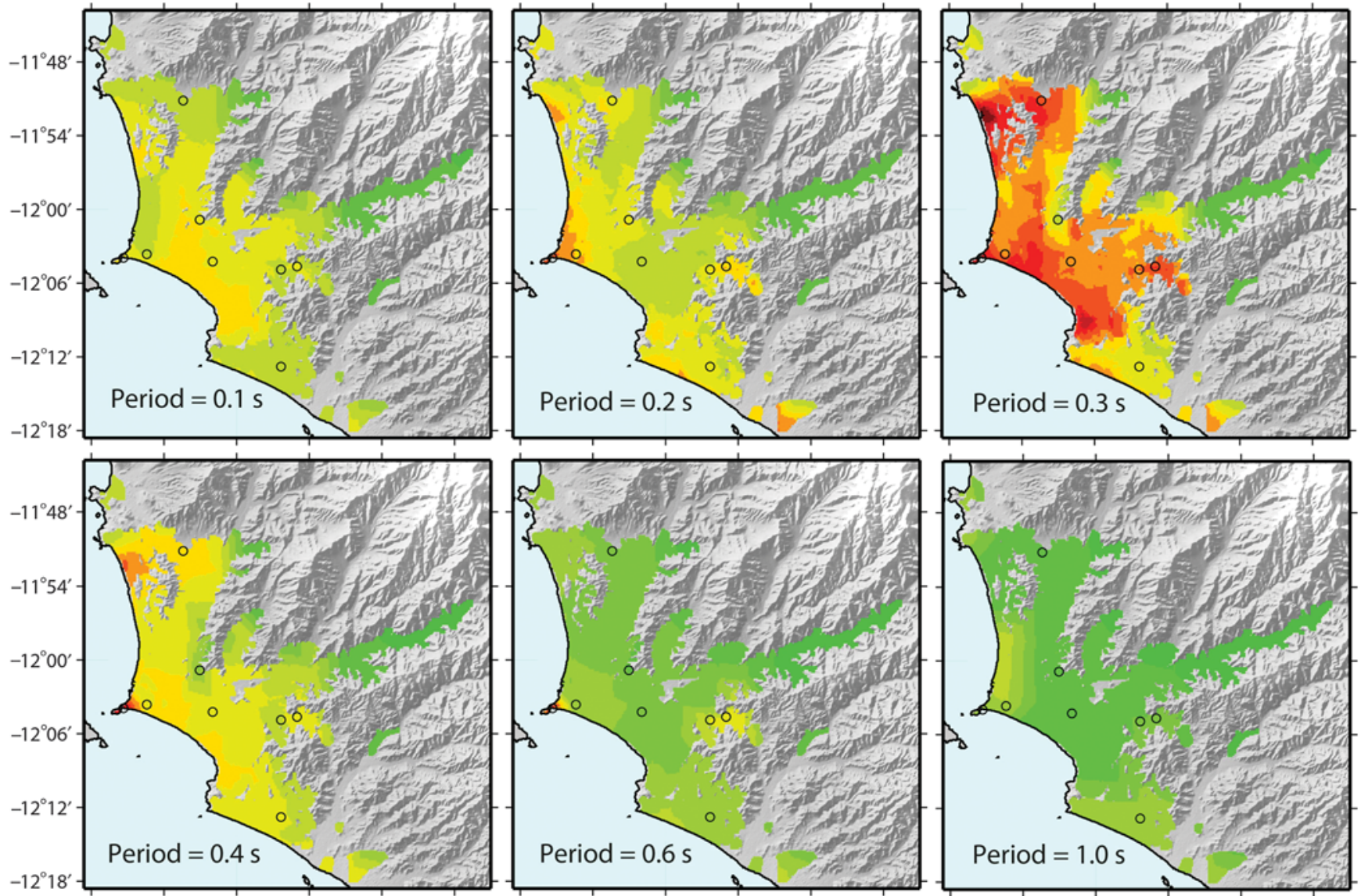

$-77^{\circ} 12^{\prime}-77^{\circ} 06^{\prime}-77^{\circ} 00^{\prime}-76^{\circ} 54^{\prime}-76^{\circ} 48^{\prime}-76^{\circ} 42^{\prime}-77^{\circ} 12^{\prime}-77^{\circ} 06^{\prime}-77^{\circ} 00^{\prime}-76^{\circ} 54^{\prime}-76^{\circ} 48^{\prime}-76^{\circ} 42^{\prime}-77^{\circ} 12^{\prime}-77^{\circ} 06^{\prime}-77^{\circ} 00^{\prime}-76^{\circ} 54^{\prime}-76^{\circ} 48^{\prime}-76^{\circ} 42^{\prime}$

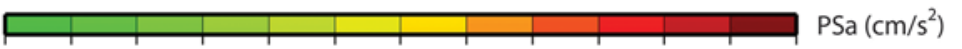

$0 \quad 20040060080010001200140016001800200022002400$

Figure 15. Maps of average pseudospectral accelerations (PSA) (vectorial summation of simulated east-west and north-south components) in metropolitan Lima for all scenarios and for selected values of period, including shallow site effects.

2003), sediment thickness at world trenches, and upper plate strains at ocean margins (Heuret et al., 2012), as well as the relationship between earth tidal stresses and seismicity in subduction zones (Tanaka, 2012).

In our study, the interseismic coupling model provides the long-wavelength features of slip for our scenario earthquakes. It is therefore important to analyze the impact of this information on the strong-motion simulations. To reach this purpose, we constructed 12 purely stochastic slip (SS) models using the Von Karman PSD obtained in this study and assuming the same nine hypocenters used for the scenarios in this article. The stochastic slips are based on the shortwavelength models (SWM) used to construct the 12 broadband scenario slips (BBS) (i.e., Fig. 3b). As the SWM fluctuate around zero, to construct the stochastic slip models we assign a value of zero to negative values of slip. We calculated stress drop and rise-time distributions of SS in the same way as for the BBS. Then we simulated the broadband frequency ground motions in central Lima for the 1D crustal velocity model in Table 1, for all SS and fault ruptures
(108 models). In Figure 17, we show the velocity response spectra $\left(S_{v}\right)$ of the simulated ground motions for the stochastic slip used to construct broadband Slip 5 (Fig. 6), averaged for all fault-rupture models (nine hypocenters). Red lines correspond to the $S_{v}$ of stochastic slip and black lines to the $S_{v}$ of broadband slip. Continuous lines correspond to the east-west component and dashed lines to the north-south component. From this figure, we can observe that for the SS models, large amplitudes of $S_{v}$ (up to $\sim 50 \mathrm{~cm} / \mathrm{s}$ ) are obtained for periods smaller than $3 \mathrm{~s}$. For longer periods the $S_{v}$ values decrease to $\sim 20 \mathrm{~cm} / \mathrm{s}$. On the other hand, $S_{v}$ for the BBS displays a significant increase for periods longer than $3 \mathrm{~s}$, reaching a maximum $S_{v}$ value of $\sim 70 \mathrm{~cm} / \mathrm{s}$ at a period around $20 \mathrm{~s}$. The amplitude characteristics of $S_{v}$ for other SS and BBS models display a similar behavior to the one for Slip 5, although we observed a large variability in $S_{v}$ amplitudes. These calculations indicate that the interseismic coupling model (long-wavelength slip) has a very important contribution for ground motions at long periods (3-20 s), which might be important when considering its impact to 

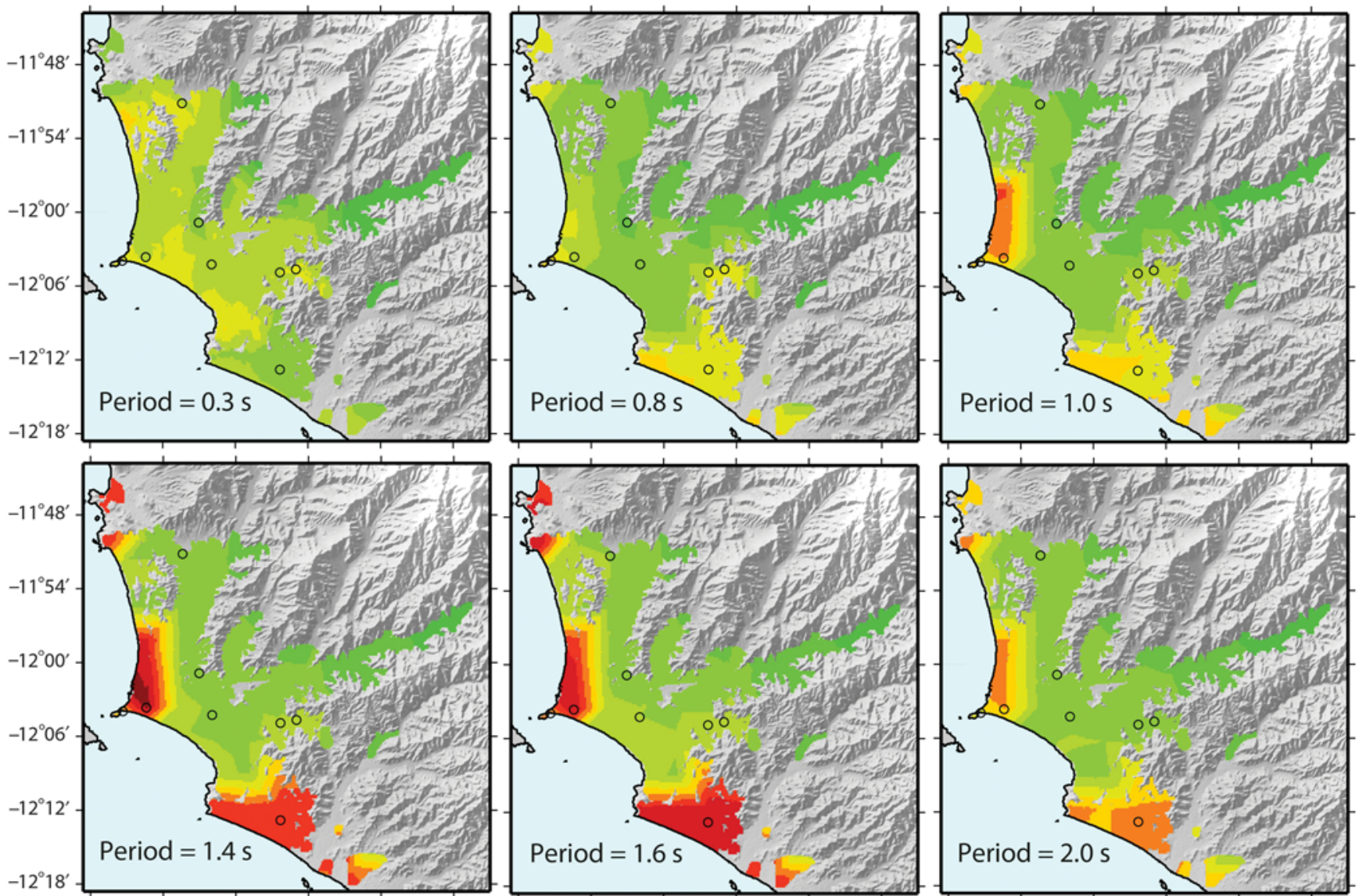

$-77^{\circ} 12^{\prime}-77^{\circ} 06^{\prime}-77^{\circ} 00^{\prime}-76^{\circ} 54^{\prime}-76^{\circ} 48^{\prime}-76^{\circ} 42^{\prime}-77^{\circ} 12^{\prime}-77^{\circ} 06^{\prime}-77^{\circ} 00^{\prime}-76^{\circ} 54^{\prime}-76^{\circ} 48^{\prime}-76^{\circ} 42^{\prime}-77^{\circ} 12^{\prime}-77^{\circ} 06^{\prime}-77^{\circ} 00^{\prime}-76^{\circ} 54^{\prime}-76^{\circ} 48^{\prime}-76^{\circ} 42^{\prime}$

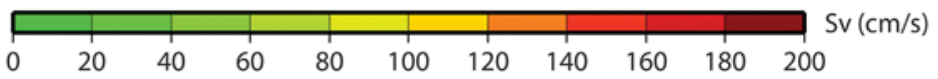

Figure 16. Maps of average $S_{v}$ (vectorial summation of simulated east-west and north-south components) in metropolitan Lima for all scenarios and for selected values of period, including shallow site effects.

high-rise buildings with heights above $\sim 100 \mathrm{~m}$ in Lima $(\sim 5$ buildings to 2014/7). On the other hand, long-wavelength slips are also important for the simulation of tsunamis, as indicated by simulations carried out for Lima city (Adriano et al., 2013).

Our simulation methodology is limited to $1 \mathrm{D}$ velocity models. We are aware that 3D effects in ground motion from sedimentary wedges in subduction zones as well as 3D basin structures (Yamada and Iwata, 2005; Olsen et al., 2008) are important. However, our microtremors survey results indicate that $V_{S}$ reaches $3 \mathrm{~km} / \mathrm{s}$ at depths shallower than $250 \mathrm{~m}$ for most of Lima city (and at depths around $750 \mathrm{~m}$ along the coast). We therefore considered that the $1 \mathrm{D}$ velocity model might be appropriate for Lima. On the other hand, Lima soil is composed of very dense gravels so amplifications due to site effects are small (Fig. 10). Furthermore, subduction processes along the Peruvian margin are dominated by tectonic erosion leading to narrow sedimentary wedges (Krabbenhoft et al., 2004), in contrast to the large sedimentary wedges that characterize the accretionary subductions, such as the Nankai region, Japan (Nakanishi et al., 2002). To judge the likelihood of the severest strong ground-motions simulations obtained for Lima city in our study (PGA and PGV values above $1000 \mathrm{~cm} / \mathrm{s}^{2}$ and $100 \mathrm{~cm} / \mathrm{s}$, respectively), we compared them with macroseismic intensity estimations of the 1746 earthquake. During this earthquake, Lima likely experienced MMI values above IX (Silgado, 1978; Alva et al., 1984) (inset in Fig. 18), which would roughly correspond to PGA and PGV values of $800 \mathrm{~cm} / \mathrm{s}^{2}$ and $80 \mathrm{~cm} / \mathrm{s}$, respectively (Wald et al., 1999). Thus these observations may suggest that a replication of the 1746 earthquake ( $\sim$ M 9 ) could generate ground motions in Lima as large as the ones predicted by our worst groundmotion simulation scenario (Figs. 11 and 18).

In our study, we estimate that the severest simulated ground motions in Lima originate from the source models with the largest amount of slip beneath the city, at a depth of approximately $40 \mathrm{~km}$ (slips number 5 and 10). This could be an important criterion for selection of slip scenarios that might be significant in terms of shaking for future megathrust earthquakes. Strong ground motions in Japan during the Tohoku-Oki earthquake were actually controlled by the 


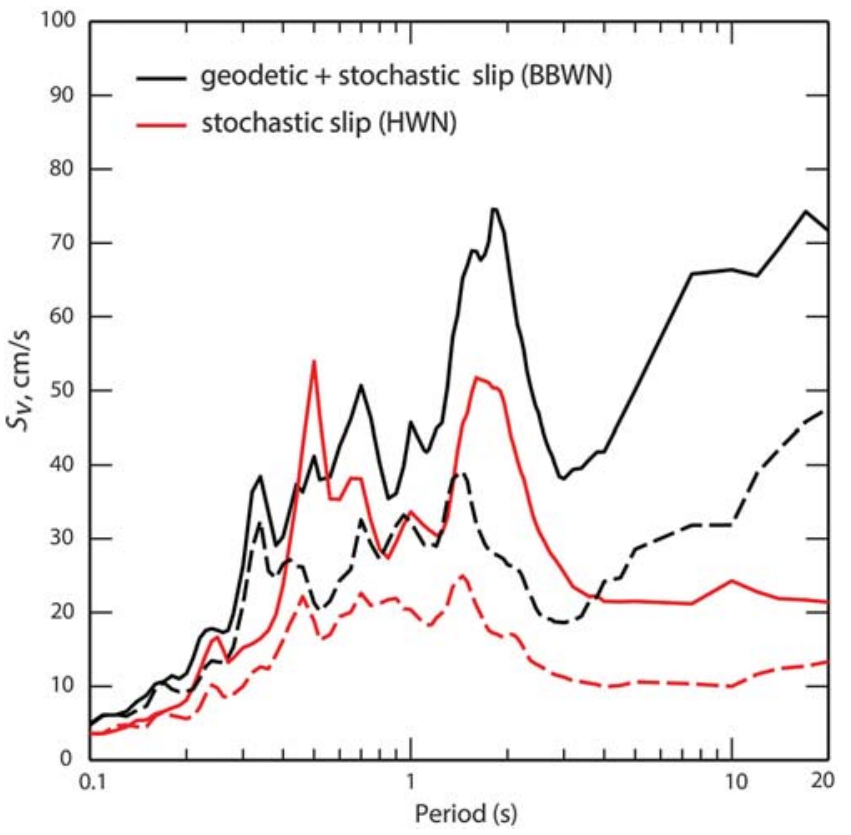

Figure 17. Velocity response spectra $\left(S_{v}\right)$ of the simulated ground motions for the stochastic slip used to construct broadband Slip 5 (Fig. 6), averaged for all fault-rupture models. Simulations correspond to a seismic bedrock condition $\left(V_{S}=3454 \mathrm{~m} / \mathrm{s}\right)$. Red lines correspond to the $S_{v}$ of stochastic slip and black lines to the $S_{v}$ of broadband slip. Continuous lines correspond to the east-west component and dashed lines to the north-south component.

deeper portions of the megathrust $(\sim 30-50 \mathrm{~km})$, where most of the high-frequency radiation originated (Kurahashi and Irikura, 2011; Kumagai et al., 2013). A similar along-dip segmentation of shallow long-period and deeper short-period radiations was also observed for the 2007 Pisco earthquake in Peru (Sufri et al., 2012; Pulido et al., 2013). This type of bimodal behavior in ground motions may highlight the need for dynamic fault-rupture models that consider variability of fault properties (Pulido and Dalguer, 2009) or depthdependent stress (Roten et al., 2011).

\section{Conclusions}

We have developed an original methodology for the estimation of slip scenarios for megathrust earthquakes combining models of interseismic coupling distribution in subduction margins obtained from geodetic data, information of historical earthquakes, as well as spatially correlated random noise distributions representing small-scale heterogeneities of slip. Our application of the method to central Peru coast, where a huge tsunami occurred in 1746, and where high interseismic velocities are still observed (Nocquet et al., 2014), suggest an upper-bound earthquake scenario for a megathrust rupture in central Peru with an $M_{\mathrm{w}} 8.9$, a source rupture area of approximately $500 \mathrm{~km}$ along strike and $165 \mathrm{~km}$ along dip and a peak slip of $16 \mathrm{~m}$. The slip model obtained from geodetic data represents the large-scale features of asperities within the megathrust,

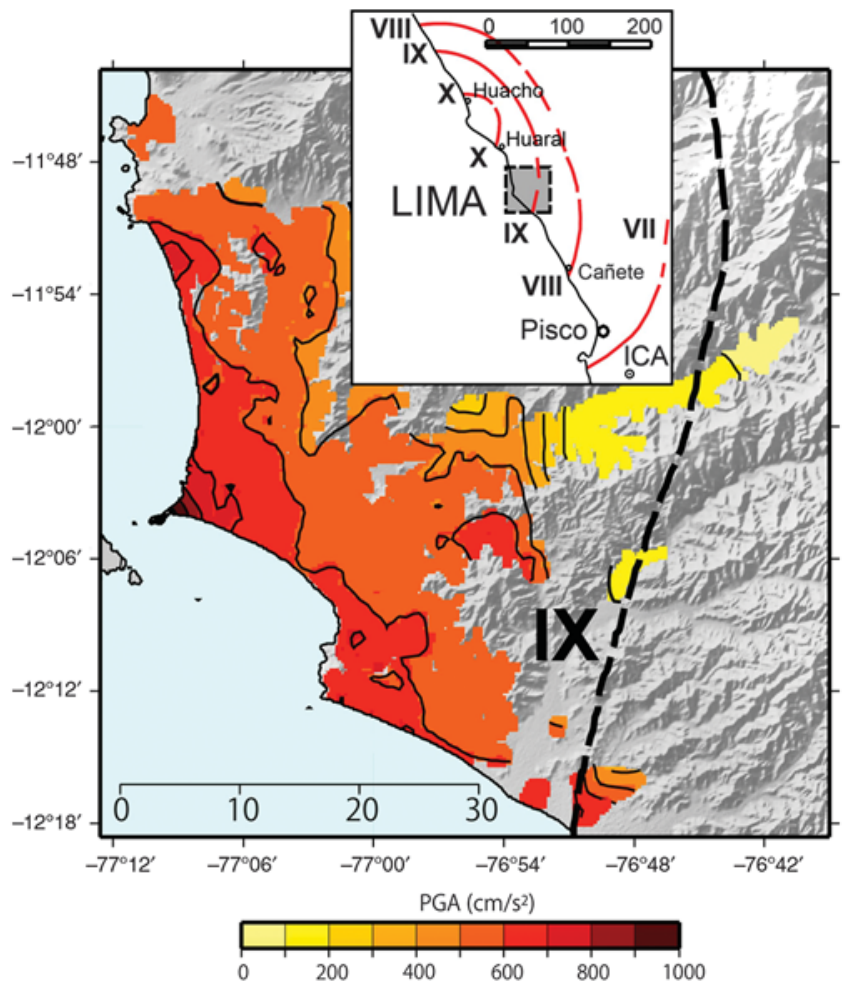

Figure 18. Average plus one sigma PGA map for Lima for all scenarios, including shallow site effects. The inset shows the macroseismic intensity distribution for the 1746 earthquake in central Peru (Alva et al., 1984).

which is appropriate for simulation of long-period waves and tsunami modeling. For the simulation of strong ground motion, we propose broadband source models constructed by adding short-wavelength slip distributions obtained from a Von Karman PSD function with random phases, to the slip model inferred from geodetic data.

We calculated a set of strong ground motions in Lima for 108 fault-rupture scenarios, and incorporated site effects obtained from microtremors surveys conducted at representative geotechnical zones in metropolitan Lima. Average PGA and PGV in Lima for all scenarios reach $700 \mathrm{~cm} / \mathrm{s}^{2}$ and $70 \mathrm{~cm} / \mathrm{s}$, respectively, but these values can be as large as $1000 \mathrm{~cm} / \mathrm{s}^{2}$ and $100 \mathrm{~cm} / \mathrm{s}$ for ground motions one standard deviation above the mean. These ground-motion amplitudes are comparable to the intensities inferred for Lima during the great 1746 earthquake (MMI $\sim$ IX).

Our results indicate that the average PGA and PGV in central Lima (hard soil site) for our simulations are about 2 to 3 times larger than the observed values during the 1974 and 1966 earthquakes $\left(M_{\mathrm{w}} 8.0\right)$. Simulated spectral values at central Lima are as large as four times the values observed during the 1974 and 1966 earthquakes.

Values of average pseudoacceleration response spectra for Lima obtained in this study are above $1.5 \mathrm{~g}$ for periods around $0.3 \mathrm{~s}$, for wide areas within the city. This could be a critical issue in terms of damage if an earthquake of the 
characteristics considered in this study hits Lima, taking into account that the majority of structures in metropolitan Lima are typically low- to midrise masonry or reinforced concrete buildings.

This work is not implying that an $\mathbf{M} 9$ class event would occur soon in central Peru. However, it is aimed at exploring a series of megathrust earthquake scenarios and their associated ground shaking maps for an event of similar size to the great 1746 earthquake, which probably contributed to the decline of the Spanish invasion. We explore extreme seismic scenarios to highlight the districts of Lima megacity that may suffer strong ground shaking. We hope results of our study can help local authorities in Lima undertake appropriate countermeasures.

\section{Data and Resources}

The intensity distribution from the 1746 Lima earthquake in Figure 17 was obtained from the historical earthquakes intensity database of the Universidad Nacional de Ingeniería, Perú, http://www.cismid-uni.org/redacis/isosistas.php (last accessed April 2014). Strong-motion records of the 1966 and 1974 Lima earthquakes were downloaded from the Universidad Nacional de Ingeniería, Centro Peruano Japonés de Investigaciones Sísmicas y Mitigación de Desastres (CISMID-UNI) strong-motion database, http://www.cismid-uni.org/redacis/b_ usgs.php (last accessed April 2014). Many of the figures were prepared using the Generic Mapping Tools, https://www. soest.hawaii.edu/gmt/ (last accessed April 2011).

\section{Acknowledgments}

This study was supported by the SATREPS project "Enhancement of Earthquake and Tsunami Mitigation Technology in Peru" and the National Research Institute for Earth Science and Disaster Prevention project "Development of Monitoring and Forecasting Technology for Crustal Activity." We thank the Associate Editor Ivan G. Wong and two anonymous reviewers for very helpful comments. We also thank Hugo Perfettini for insightful discussions at an early stage of this study.

\section{References}

Aagaard, B. T., R. W. Graves, D. P. Schwartz, D. A. Ponce, and R. W. Graymer (2010). Ground-motion modeling of Hayward fault scenario earthquakes, Part I: Construction of the suite of scenarios, Bull. Seismol. Soc. Am. 100, no. 6, 2927-2944, doi: 10.1785/0120090324.

Adriano, B., E. Mas, S. Koshimura, Y. Fujii, S. Yauri, C. Jimenez, and H. Yanagisawa (2013). Tsunami inundation mapping in Lima for two tsunami source scenarios, J. Disas. Res. 8, no. 2, 274-284.

Alva Hurtado, J. E., J. Meneses, and V. Guzmán (1984). Distribución de máximas intensidades sísmicas observadas en el Perú, V Congreso Nacional de Ingeniería Civil, Tacna, Perú, http://www.cismid-uni.org/ redacis/isosistas.php (last accessed April 2014).

Beck, S. L., and S. P. Nishenko (1990). Variations in the mode of great earthquake rupture along the central Peru subduction zone, Geophys. Res. Lett. 17, 1969-1972.

Beck, S. L., and L. J. Ruff (1989). Great earthquakes and subduction along the Peru trench, Phys. Earth Planet. In. 57, nos. 3/4, 199-224, doi: 10.1016/0031-9201(89)90112-X.

Béjar-Pizarro, M., A. Socquet, R. Armijo, D. Carrizo, J. Genrich, and M. Simons (2013). Andean structural control on interseismic coupling in the North Chile subduction zone, Nature Geosci. 6, 462-467, doi: 10.1038/NGEO1802.

Boore, D. M. (2003). Simulation of ground motion using the stochastic method, Pure Appl. Geophys. 160, 635-676.

Bouchon, M. (1981). A simple method to calculate Green's functions in elastic layered media, Bull. Seismol. Soc. Am. 71, 959-971.

Brocher, T. (2008). Key elements of regional seismic velocity models for long period ground motion simulations, J. Seismol. 12, 217-221.

Calderon, D. (2012). Dynamic characteristics of the soils in Lima, Peru, by estimating shallow and deep shear-wave velocity profiles, Doctoral thesis in engineering, Graduate School of Engineering, Chiba University, Chiba, Japan, 113.

Calderon, D., Z. Aguilar, F. Lazares, T. Sekiguchi, and S. Nakai (2013). Estimation of deep shear-wave velocity profiles in Lima, Peru, using seismometers arrays, J. Disast. Res. 8, no. 2, 252-258.

Calderon, D., T. Sekiguchi, S. Nakai, Z. Aguilar, and F. Lazares (2012). Study of soil amplification based on microtremor and seismic records in Lima Peru, J. Japan Assoc. Earthq. Eng. 12, no. 2, 1-20.

Causse, M., F. Cotton, and P. M. Mai (2010). Constraining the roughness degree of slip heterogeneity, J. Geophys. Res. 115, no. B05304, doi: 10.1029/2009JB006747.

Chlieh, M., J. P. Avouac, K. Sieh, D. H. Natawidjaja, and J. Galetzka (2008). Heterogeneous coupling of the Sumatran megathrust constrained by geodetic and paleogeodetic measurements, J. Geophys. Res. 113, no. B05305, doi: 10.1029/2007JB004981.

Chlieh, M., J. B. de Chabalier, J. C. Ruegg, R. Armijo, R. Dmowska, J. Campos, and K. L. Feigl (2004). Crustal deformation and fault slip during the seismic cycle in the North Chile subduction zone, from GPS and InSAR observations, Geophys. J. Int. 158, no. 2, 695-711.

Chlieh, M., H. Perfettini, H. Tavera, J.-P. Avouac, D. Remy, J.-M. Nocquet, F. Rolandone, F. Bondoux, G. Gabalda, and S. Bonvalot (2011). Interseismic coupling and seismic potential along the central Andes subduction zone, J. Geophys. Res. 116, no. B12405, doi: 10.1029/2010JB008166.

Delouis, B., J. Nocquet, and M. Vallée (2010). Slip distribution of the February 27, 2010 $M_{\mathrm{w}} 8.8$ Maule earthquake, central Chile, from static and high-rate GPS, InSAR, and broadband teleseismic data, Geophys. Res. Lett. 37, L17305, doi: 10.1029/2010GL043899.

Dorbath, L., A. Cisternas, and C. Dorbath (1990). Assessment of the size of large and great historical earthquakes in Peru, Bull. Seismol. Soc. Am. 80, no. 3, 551-576.

Dorbath, L., C. Dorbath, E. Jimenez, and L. Rivera (1991). Seismicity and tectonic deformation in the Eastern cordillera and the sub-andean zone of central Peru, J. S. Am. Earth Sci. 4, nos. 1/2, 13-24.

Frankel, A. (2013). Comment on "Why earthquake hazard maps often fail and what to do about it" by S. Stein, R. Geller, and M. Liu, Tectonophysics 592, 200-206, doi: 10.1016/j.tecto.2012.11.032.

Gagnon, K., C. D. Chadwell, and E. Norabuena (2005). Measuring the onset of locking in the Peru-Chile trench with GPS and acoustic measurements, Nature 434, no. 7030, 205-208, doi: 10.1038/nature03412.

Graves, R. W., and A. Pitarka (2010). Broadband ground-motion simulation using a hybrid approach, Bull. Seismol. Soc. Am. 100, no. 5A, 20952123, doi: $10.1785 / 0120100057$.

Graves, R. W., B. T. Aagaard, and K. W. Hudnut (2010). The ShakeOut earthquake source and ground motion simulations, Earthq. Spectra 27, no. 2, 273-291, doi: 10.1193/1.3570677.

Hashimoto, C., A. Noda, T. Sagiya, and M. Matsuura (2009). Interplate seismogenic zones along the Kuril-Japan trench inferred from GPS data inversion, Nat. Geosci. 2, 141-144, doi: 10.1038/NGEO421.

Heuret, A., C. P. Conrad, F. Funiciello, S. Lallemand, and L. Sandri (2012). Relation between subduction megathrust earthquakes, trench sediment thickness and upper plate strain, Geophys. Res. Lett. 39, L05304 doi: 10.1029/2011GL050712.

Irikura, K. (1986). Prediction of strong acceleration motion using empirical Green's function, 7th Japan Earthq. Eng. Symp., Tokyo, 151-156.

Irikura, K., and K. Kamae (1994). Estimation of strong motion in broadfrequency band based on a seismic source scaling model and empirical Green's function technique, Ann. Geofisc. 37, 1721-1743. 
Jones, N. (2014). Global seismic network takes to the seas: Two systems could plug the ocean-sized gap in earthquake detection, Nature 507, 151, doi: 10.1038/507151a.

Kendrick, E., M. Bevis, J. R. Smalley, B. Brooks, R. B. Vargas, E. Lauria, and L. P. S. Fortes (2003). The Nazca-South America Euler vector and its rate of change, J. S. Am. Earth Sci. 16, no. 2, 125-131, doi: 10.1016/S0895-9811(03)00028-2.

Konca, A. O., J. P. Avouac, A. Sladen, A. J. Meltzner, K. Sieh, P. Fang, Z. Li, J. Galetzka, J. Genrich, M. Chlieh, et al. (2008). Partial rupture of a locked patch of the Sumatra megathrust during the 2007 earthquake sequence, Nature 456, 631-635, doi: 10.1038/nature07572.

Krabbenhoft, A., J. Bialas, H. Kopp, N. Kukowski, and C. Hubscher (2004). Crustal structure of the Peruvian continental margin from wide-angle seismic studies, Geophys. J. Int. 159, 749-764, doi: 10.1111/j.1365246X.2004.02425.x.

Kumagai, H., N. Pulido, E. Fukuyama, and S. Aoi (2013). High-frequency source radiation during the 2011 Tohoku-Oki earthquake, Japan, inferred from KiK-net strong-motion seismograms, J. Geophys. Res. 118, doi: 10.1029/2012JB009670.

Kurahashi, S, and K. Irikura (2011). Source model for generating strong ground motions during the 2011 off the Pacific coast of Tohoku Earthquake, Earth Planets Space 63, 571-576.

Lay, T., C. J. Ammon, H. Kanamori, K. D. Koper, O. Sufri, and A. R. Hutko (2010). Teleseismic inversion for rupture process of the 27 February 2010 Chile $\left(M_{\mathrm{w}} 8.8\right)$ earthquake, Geophys. Res. Lett. 37, L13301, doi: 10.1029/2010GL043379.

Lorito, S., F. Romano, S. Atzori, X. Tong, A. Avallone, J. McCloskey, M. Cocco, E. Boschi, and A. Piatanesi (2011). Limited overlap between the seismic gap and coseismic slip of the great 2010 Chile earthquake, Nat. Geosci. 4, doi: 10.1038/NGEO1073.

Loveless, J. P., and B. J. Meade (2011). Spatial correlation of interseismic coupling and coseismic rupture extent of the $2011 M_{\mathrm{w}} 9.0$ Tohoku-oki earthquake, Geophys. Res. Lett. 38, no. 17, doi: 10.1029/2011GL048561.

Mai, P. M., P. Spudich, and J. Boatwright (2005). Hypocenter locations in finite-source rupture models, Bull. Seismol. Soc. Am. 95, 965-980, doi: 10.1785/0120040111

Matsuoka, M., H. Miura, S. Midorikawa, and M. Estrada (2013). Extraction of urban information for seismic hazard and risk assessment in Lima, Peru using satellite imagery, J. Disast Res. 8, no. 2, 328-345.

Moreno, M., M. Rosenau, and O. Oncken (2010). O. 2010 Maule earthquake slip correlates with pre-seismic locking of Andean subduction zone, Nature 467, 198-204.

Nakanishi, A., N. Takahashi, J. Park, S. Miura, S. Kodaira, Y. Kaneda, N. Hirata, T. Iwasaki, and M. Nakamura (2002). Crustal structure across the coseismic rupture zone of the 1944 Tonankai earthquake, the central Nankai trough seismogenic zone, J. Geophys. Res. 107, doi: 10.1029/2001JB000424

Nanjo, K. Z., N. Hirata, K. Obara, and K. Kasahara (2012). Decade-scale decrease in b value prior to the M 9-class 2011 Tohoku and 2004 Sumatra quakes, Geophys. Res. Lett. 39, L20304 doi: 10.1029/2012GL052997.

Nocquet, J.-M., J. C. Villegas-Lanza, M. Chlieh, P. A. Mothes, F. Rolandone, P. Jarrin, D. Cisneros, A. Alvarado, L. Audin, F. Bonboux, et al. (2014). Motion of continental slivers and creeping subduction in the northern Andes, Nat. Geosci. 7, 287-291, doi: 10.1038/ngeo2099.

Okada, Y. (2013). Recent progress of seismic observation networks in Japan, J. Phys. Conf. 433, 012039, doi: 10.1088/1742-6596/433/1/012039.

Okal, E. A., J. C. Borrero, and C. E. Synolakis (2006). Evaluation of tsunami risk from regional earthquakes at Pisco, Peru, Bull. Seismol. Soc. Am. 96, 1634-1648, doi: 10.1785/0120050158.

Olsen, K. B., W. J. Stephenson, and A. Geisselmeyer (2008). 3D crustal structure and long-period ground motions from a M 9.0 megathrust earthquake in the Pacific northwest region, J. Seismol. doi: 10.1007/s10950-007-9082-y.

Perfettini, H., J.-P. Avouac, H. Tavera, A. Kositsky, J.-M. Nocquet, F. Bondoux, M. Chlieh, A. Sladen, L. Audin, D. L. Farber, and P. Soler (2010). Seismic and aseismic slip on the Central Peru megathrust, Nature 465, 78-81, doi: 10.1038/nature09062.
Protti, M., V. González, A. V. Newman, T. H. Dixon, S. Y. Schwartz, J. S. Marshall, L. Feng, J. I. Walter, R. Malservisi, and S. E. Owen (2013). Nicoya earthquake rupture anticipated by geodetic measurement of the locked plate interface, Nat. Geosci. 7, 117-212, doi: 10.1038/NGEO2038.

Pulido, N., and L. Dalguer (2009). Estimation of the high-frequency radiation of the 2000 Tottori (Japan) earthquake based on a dynamic model of fault rupture: Application to the strong ground motion simulation, Bull. Seismol. Soc. Am. 99, no. 4, 2305-2322, doi: 10.1785/ 0120080165 .

Pulido, N., and T. Kubo (2004). Near-fault strong motion complexity of the 2000 Tottori earthquake (Japan) from a broadband source asperity model, Tectonophysics 390, 177-192.

Pulido, N., A. Ojeda, K. Atakan, and T. Kubo (2004). Strong ground motion estimation in the Marmara sea region (Turkey) based on a scenario earthquake, Tectonophysics 391, 357-374.

Pulido, N., H. Tavera, Z. Aguilar, S. Nakai, and F. Yamazaki (2013). Strong motion simulation of the M 8.0 August 15, 2007, Pisco earthquake; Effect of a multi-frequency rupture process, J. Disast. Res. 8, no. 2, 235-242.

Pulido,, N., Y. Yagi, H. Kumagai, and N. Nishimura (2011). Rupture process and coseismic deformations of the February 2010 Maule earthquake, Chile, Earth Planets Space 63, 955-959.

Quispe, G., H. Yamanaka, Z. Aguilar, F. Lazares, and H. Tavera (2013). Preliminary analysis for evaluation of local site effects in Lima city, Peru from ground motion data by using the spectral inversion method, J. Disast. Res. 8, no. 2, 243-251.

Ripperger, J., and P. M. Mai (2004). Fast computation of static stress changes on 2D faults from final slip distributions, Geophys. Res. Lett. 31, L18610, doi: 10.1029/2004GL020594.

Rodriguez-Marek, A., F. Cotton, N. A. Abrahamson, S. Akkar, L. A. Atik, B. Edwards, G. Montalva, and H. M. Dawood (2013). A model for singlestation standard deviation using data from various tectonic regions, Bull. Seismol. Soc. Am. 103, 3149-3163, doi: 10.1785/0120130030.

Roten, D., K. B. Olsen, J. C. Pechmann, V. M. Cruz-Atienza, and H. Magistrale (2011). 3D simulations of M 7 earthquakes on the Wasatch fault, Utah, part I: Long-period (0-1 Hz) ground motion, Bull. Seismol. Soc. Am. 101, no. 5, 2045-2063.

Schnabel, P. B., J. Lysmer, and H. B. Seed (1972). SHAKE-A computer program for earthquake response analysis of horizontally layered sites, EERC Report No. 72-12, Earthquake Engineering Research Center, University of California, Berkeley, California, $92 \mathrm{pp}$.

Sekiguchi, T., D. Calderon, S. Nakai, Z. Aguilar, and F. Lazares (2013). Evaluation of surface soil amplification for wide areas in Lima, Peru, J. Disast. Res. 8, no. 2, 259-265.

Silgado, E. (1978). Historia de los sismos más notables ocurridos en el Perú (1513-1974), Instituto de Geología y Minería, Boletín No. 3, Serie C, Geodinámica e Ingeniería Geológica, Lima, Perú.

Song, T. A., and M. Simons (2003). Large trench-Parallel gravity variations predict seismogenic behavior in subduction zones, Science 301, 630, doi: 10.1126/science.1085557.

Sorensen, M. B., K. Atakan, and N. Pulido (2007). Simulated strong ground motions for the great M 9.3 Sumatra-Andaman earthquake of December 26, 2004, Bull. Seismol. Soc. Am. 97, no. 1A, S139-S151, doi: 10.1785/0120050608.

Sorensen, M. B., N. Pulido, and K. Atakan (2007). Sensitivity of groundmotion simulations to earthquake source parameters: A case study for Istanbul, Turkey, Bull. Seismol. Soc. Am. 97, 881-900, doi: 10.1785/ 0120060044.

Sufri, O., K. D. Koper, and T. Lay (2012). Along-dip seismic radiation segmentation during the $2007 M_{\mathrm{w}} 8.0$ Pisco," Peru earthquake, Geophys. Res. Lett. 39, L08311, doi: 10.1029/2012GL051316.

Tanaka, S. (2012). Tidal triggering of earthquakes prior to the 2011 TohokuOki earthquake $\left(M_{\mathrm{w}}\right.$ 9.1), Geophys. Res. Lett. 39, L00G26, doi: 10.1029/2012GL051179.

Tavera, H., and I. Bernal (2005). Distribución espacial de áreas de ruptura y lagunas sísmicas en el borde oeste del Perú, Volumen Especial $\mathrm{N}^{\circ} 6$ Alberto Giesecke Matto, 89-102. 
Wald, D. J., V. Quitoriano, T. H. Heaton, and H. Kanamori (1999). Relationships between peak ground acceleration, peak ground velocity, and modified Mercalli intensity in California, Earthq. Spectra 15, no. 3, 557-564.

Yamada, N., and T. Iwata (2005). Long-period ground motion simulation in the Kinki area during the $M_{\mathrm{j}} 7.1$ foreshock of the 2004 off the Kii peninsula earthquakes, Earth Planets Space 57, 197-202.

National Research Institute for Earth Science and Disaster Prevention

3-1 Tennodai, Tsukuba

Ibaraki 305-0006, Japan

nelson@bosai.go.jp

(N.P.)

Universidad Nacional de Ingeniería

Av. Túpac Amaru N ${ }^{\circ}$ 1150-Lima 25

Apartado Postal 31-250

Lima 31, Perú

(Z.A., D.C.)

\author{
Instituto Geofísico del Perú \\ Calle Bajadoz $\mathrm{N}^{\circ} 169$ \\ Urbanización Mayorazgo IV Etapa \\ Ate Vitarte, Lima, Perú \\ (H.T.)
}

University Nice-Sophia

Géoazur, 250 rue Albert Einstein

Sophia Antipolis, 06560 Valbonne, France

(M.C.)

\section{Chiba University \\ 1-33 Yayoi-cho, Inage-ku \\ Chiba 263-8522, Japan}

(T.S., S.N., F.Y.)
Manuscript received 10 April 2014;

Published Online 13 January 2015 